\title{
Esnek Yol Kaplama Tabakalarında Kullanılan Geri Dönüştürülmüş Beton Agregalarının Ağır Trafik Yükleri Altında Doğrusal Olmayan Davranışının Deneysel ve Sayısal İncelenmesi
}

\author{
Merve AKBAȘ $^{1 *}$, Bilal ÖZASLAN ${ }^{2}$, Hadi KHANBABAZADEH ${ }^{3}$, Recep İYISAN ${ }^{4}$

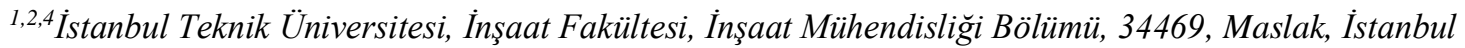 \\ ${ }^{3}$ Gebzel Teknik Üniversitesi, Mühendislik Fakültesi, İnşaat Mühendisliği Bölümü, 41400, Gebze, Kocaeli \\ (ORCID: 0000-0001-8466-2463) (ORCID: 0000-0001-7951-1759) \\ (ORCID: 0000-0001-9764-7799) (ORCID: 0000-0002-0887-9983)
}

\begin{abstract}
$\ddot{\mathbf{O z}}$
İnşaat yıkım atıklarından elde edilen geri dönüştürülmüş beton agregalarının (GDBA) yol dolgularında kullanımı, doğal agrega talebini azaltmakta, ekonomik ve çevre dostu tasarımlarla geleneksel esnek yol kaplamanın uzun dönem performansını iyileştirmektedir. Bu çalışmada, temel ve alt temel tabakalarında \%100 GDBA kullanımının esnek yol kaplama tabakalarının mekanik davranışına etkileri araştırılmıştır. $\mathrm{Bu}$ amaçla önce GDBA'nın özelliklerinin belirlendiği bir laboratuvar çalışması yürütülmüş sonrasında ağır trafik yükleri altında bitümlü sıcak karışım tabaka kalınlığının da etkisi dikkate alınarak GDBA'nın uzun dönem performansını değerlendiren 3 boyutlu doğrusal olmayan sayısal analizler yapılmıştır. Laboratuvar çalışması kapsamında, hazırlanan temel ve alt temel numunelerinin geoteknik özellikleri ile birlikte, esneklik modülü ve kalıcı deformasyon deneyleri uygulanarak esneklik özellikleri belirlenmiştir. Esneklik modülünün tahmin edildiği üç farklı model kullanılarak elde edilen sonuçlar karşılaştırılmış ve en uygun model sayısal analizlerde kullanılmıştır. Sonlu farklar yöntemine dayanan sayısal analizlerle, geleneksel esnek yol kaplama tabakalarının ağır trafik yükleri altında birikmiş plastik deformasyonları (tekerlek izi) belirlenmiştir. Deney sonuçlarından, GDBA'nın doğal agregalara kıyasla daha yüksek esneklik modülü ve daha düşük plastik deformasyon değerlerine sahip olduğu belirlenmiştir. Sayısal analiz sonuçları ise \%100 GDBA kullanılarak inşa edilen temel ve alt temel tabakalarının mekanik performansının ve tekerlek izi değerlerinin ilgili şartnamelerde belirtilen gereksinimleri karşıladığını göstermektedir. Görece daha ince seçilen bitümlü sıcak karışım tabakası altında, tandem yükleme sırasında asal gerilmelerin dönmesi ve kenarlardaki düşük kayma gerilmeleri nedeniyle deplasmanların yol merkezine doğru arttığı, bu tabaka kalınlığının artmasıyla kalıcı deformasyonların yaklaşık \%50 azaldığı ve çoklu tekerlekler altındaki deplasmanların birbirine yaklaştığı belirlenmiştir. Deneysel ve sayısal inceleme sonucunda, GDBA'nın temel ve alt temel tabakalarında dolgu malzemesi olarak kullanımının uygun olduğu anlaşılmaktadır.
\end{abstract}

Anahtar kelimeler: GDBA, Esnek Yol Kaplaması, Esneklik Modülü, 3B Nonlineer Analiz, Tekerlek izi.

\section{Experimental and Numerical Investigation of Nonlinear Behavior of Recycled Concrete Aggregates used in Flexible Pavement Courses under Heavy Traffic Load}

\begin{abstract}
The use of recycled concrete aggregates (RCA) obtained from construction demolition wastes in road embankments reduces the demand for natural aggregate, improves the long-term performance of conventional flexible road pavements with economical and environmentally friendly designs. In this study, the effects of using $100 \%$ RCA in the base and subbase courses on the mechanical behavior of the flexible pavement was investigated. For this purpose, firstly a laboratory study characterizing the properties of RCA was carried out and after that a 3dimensional nonlinear numerical analysis evaluating the long-term performance of RCA under heavy traffic loads have been done by considering the effect of asphalt coating thickness. In the laboratory study, the stiffness properties of the samples were obtained by applying the resilient modulus and permanent deformation tests together with the determination of the classical geotechnical properties. The results obtained by using three different models in which the resilient modulus was estimated were compared and the most suitable model was
\end{abstract}

"Sorumlu yazar: akbasm@itu.edu.tr

Geliş Tarihi: 27.11.2020, Kabul Tarihi: 13.02.2021 
used in numerical analysis. The accumulated plastic deformation (rutting) of the conventional flexible pavement courses under heavy wheel loads were determined with numerical analysis based on finite difference method. From the results of the experiment, it was determined that RCA has higher resilient modulus and lower plastic deformation values compared to natural aggregates. The numerical analysis results show that the mechanical performance and rutting values of the base and subbase courses built with using $100 \%$ RCA meet the requirements specified in the relevant specifications, and that the displacements under the relatively thin hot mixture asphalt layer increased towards the center due to the rotation of the principal stresses during tandem loading and the low shear stresses at the edges, and that the accumulated permanent deformations decreased by about $50 \%$ with this layer thickness increased and the displacements under multiple wheel loads converged. It has been determined that GDBA is suitable for use as filling material in the base and subbase courses.

Keywords: RCA, Flexible Pavement, Resilient Modulus, 3D Nonlinear Analysis, Rutting.

\section{Giriș}

Geleneksel doğal malzemelerin kullanımını azaltan ve çevre dostu malzeme olarak kabul edilen geri dönüştürülmüş malzemelerin yol dolgularında kullanımı son yıllarda hızla artmaktadır [1]. Hareketli tekerlek yükleri altındaki esnek yol kaplamasının performansı, geleneksel dolgu malzemelerin (doğal agrega) birikmiş kalıcı deformasyonundan diğer bir deyişle tekerlek izinden etkilenirken, bu malzemeler yerine inşaat yıkım atıklarından (IYA) elde edilen geri dönüştürülmüş beton agregalarının (GDBA) kullanımı, esnek yol kaplamanın uzun dönem performansını iyileştirmektedir [2]. Doğal agregaların yerine veya karıştırılarak kullanılabilen bu tür geri dönüştürülmüş malzemeler, yol alt temel ve temel tabakaları için yüksek kaliteli bir alternatif olarak düşünülmektedir [3, 4].

Son y1llarda, temel ve alt temel malzemesi olarak kullanılan geri dönüştürülmüş malzemelerin esnek yol kaplama performansını etkileyen esneklik özellikleri birçok araştırmacı tarafından incelenmiştir [5-9]. Ayrıca bu geri dönüştürülmüş malzemelerin esneklik modüllerini ve plastik deformasyonlarını tahmin etmek için çeşitli modeller geliştirilmiştir [10-12]. Arulrajah vd. [13], doğal agregaların GDBA'ya kıyasla daha düşük esneklik modülüne ve daha yüksek kalıcı deformasyona sahip olduğunu göstermiştir. Pourtahmasb vd. [14], GDBA içeren sıcak asfalt karışımın esneklik modülünü tahmin etmek için bir çıkarsama sistemi kullanmıştır. Kaloop vd. [15] ise esnek yol kaplamalarında kullanılan geri dönüştürülmüş beton agregası ile geri dönüştürülmüş tuğladan oluşan karışımların esneklik modülünü tahmin etmek için bir yöntem önermiştir. Saberian ve Li [16], GDBA ve kauçuk karışımının temel ve alt temel uygulamalarında uzun süreli plastik deformasyon davranışını değerlendirmiştir. Pérez vd. [17], GDBA kullanılarak hazırlanan ve bitümle stabilize edilmiş malzemelerin (BSM) yol temel tabakasında kullanımını incelemiş ve BSM ile inşa edilecek temel tabakalarının doğal agregalar kullanılarak inşa edilen temel tabakalarına kıyasla daha düşük birikmiş plastik deformasyon (tekerlek izi) ve daha yüksek esnek modülü değerlerine sahip olduğunu belirtmiştir.

Ayrıca, geri dönüştürülmüss malzemelerin, hareketli bir tekerlek yükü altında yol üstyapı tabaklarının mekanik davranışına etkisi üzerine yapılan çalışmalar, bu konunun önemine rağmen, sınırlı sayıdadır [18, 19]. Örneğin Hu vd. [20] beton kaplamalı yol üstyapısının davranışını incelemek için çok katmanlı teoriye dayalı basit bir doğrusal elastik yöntem uygulamıştır. Pérez vd. [17], esnek yol kaplama tabalarındaki kritik konumlarda maksimum tepkileri gözlemlemek için eksenel simetrik yaklaşımı kullanarak 3 Boyutlu sayısal bir analiz gerçekleştirmiştir.

$\mathrm{Bu}$ çalışmanın temel amacı, \%100 oranında GDBA kullanılarak hazırlanan yol temel ve alt temel tabakalarının mekanik davranışını esneklik özelliklerini dikkate alarak 3 boyutlu incelemektir. $\mathrm{Bu}$ amaçla, ilk olarak temel ve alt temel numunelerinin esneklik özellikleri, laboratuvarda esneklik modülü ve kalıcı deformasyon deneyleri ile belirlenmiştir. Elde edilen deney sonuçları kullanılarak, numunelerin esneklik modülünü tahmin etmek için ise üç farklı doğrusal olmayan model kullanılmıştır. Farklı modellerden elde edilen model parametreleri karşılaştırılarak deney sonuçlarına en yakın değerleri veren model belirlenmiş ve esnek yol kaplamanın hareketli tek ve tandem tekerlek yükü altında mekanik davranışının 3 boyutlu modellenmesinde kullanılmıștır. Yol kesitinin yanal yönü boyunca eğimin sınırlı uzunluğu ve hareketli aracın farklı eksenlerinin dinamik etkileri arasındaki girişim etkisi göz ardı edildiği eksenel simetri yaklaşımı, trafik yükleri altında esnek yol kaplama davranışını incelemek için uygun bir yaklaşım olarak görülmemektedir. Bu nedenle doğrusal olmayan sayısal analizler, gelişmiş dinamik sınır koşullarını içeren, sonlu farklar yöntemine dayanan, FLAC3D yazılımı ile gerçek 3 
boyutlu olarak yapılmış, yol kaplama kalınlığının etkisi de göz önüne alınarak esnek yol üstyapısının mekanik davranışı incelenmiş, elde edilen sonuçları karşılaştırılmıştır.

\section{Materyal ve Metot}

Bu çalışmada, yol üstyapısı temel ve alt temel tabakalarında doğal agrega yerine $\% 100$ oranında GDBA kullanımının uygunluğu değerlendirilmiștir. Değerlendirilen malzemeler, İstanbul'da 2012 yılında başlayan ve halen devam etmekte olan kentsel dönüşüm projesi sonucunca oluşan IYYA'dan elde edilmiştir. Hazırlanan temel ve alt temel numunelerinin mekanik ve esneklik özellikleri kapsamlı bir laboratuvar programı ile belirlenmiş; deneysel çalışmadan elde edilen sonuçlar, GDBA kullanılarak inşa edilen temsili esnek yol üstyapının ağır yükler altında mekanik davranışının değerlendirildiği sayısal analizlerde kullanılmıștır.

\subsection{Temel ve Alt Temel Numunelerinin Geoteknik Özellikleri}

İstanbul'daki farklı binaların yıkılması ile elde edilen, maksimum nominal dane çap $30 \mathrm{~mm}$ olan geri dönüştürülmüş beton agaragarı temel ve alt temel numuneleri hazırlamak için kullanılmıştır. Özgül ağırlık, kıvam limitleri, standart ve modifiye proktor deneyleri ile farklı hidrolik eğimlerde gerçekleştirilen sabit seviyeli geçirimlilik ve büyük ölçekli kesme kutusu deneylerini kapsayan bir dizi standart zemin mekaniği laboratuvar deneyleri ilgili ASTM standartları izlenerek gerçekleştirilmiştir. $\mathrm{Bu}$ araştırmada kullanılan GDBA'nın özgül ağırlığı 2.72 olarak bulunmuştur. Kıvam limitleri deney sonuçları, tüm numunelerin plastik olmayan malzemeler olarak kabul edilebileceğini göstermiştir. Numuneler Karayolları Sinıflandırma Sistemine göre A-1-a sınıfında yer almaktadır. AASHTO Kaplama Yapıları Tasarımı Kılavuzu'na [21] göre temel ve alt temel malzemeleri için üst ve alt sınır ile hazırlanacak numuneler için seçilen dane çapı dağılım eğrileri Şekil 1'de göstermektedir. Numuneler üzerinde yapılan deneylerden elde edilen geoteknik özellikler ise Tablo 1'de özetlenmiştir.

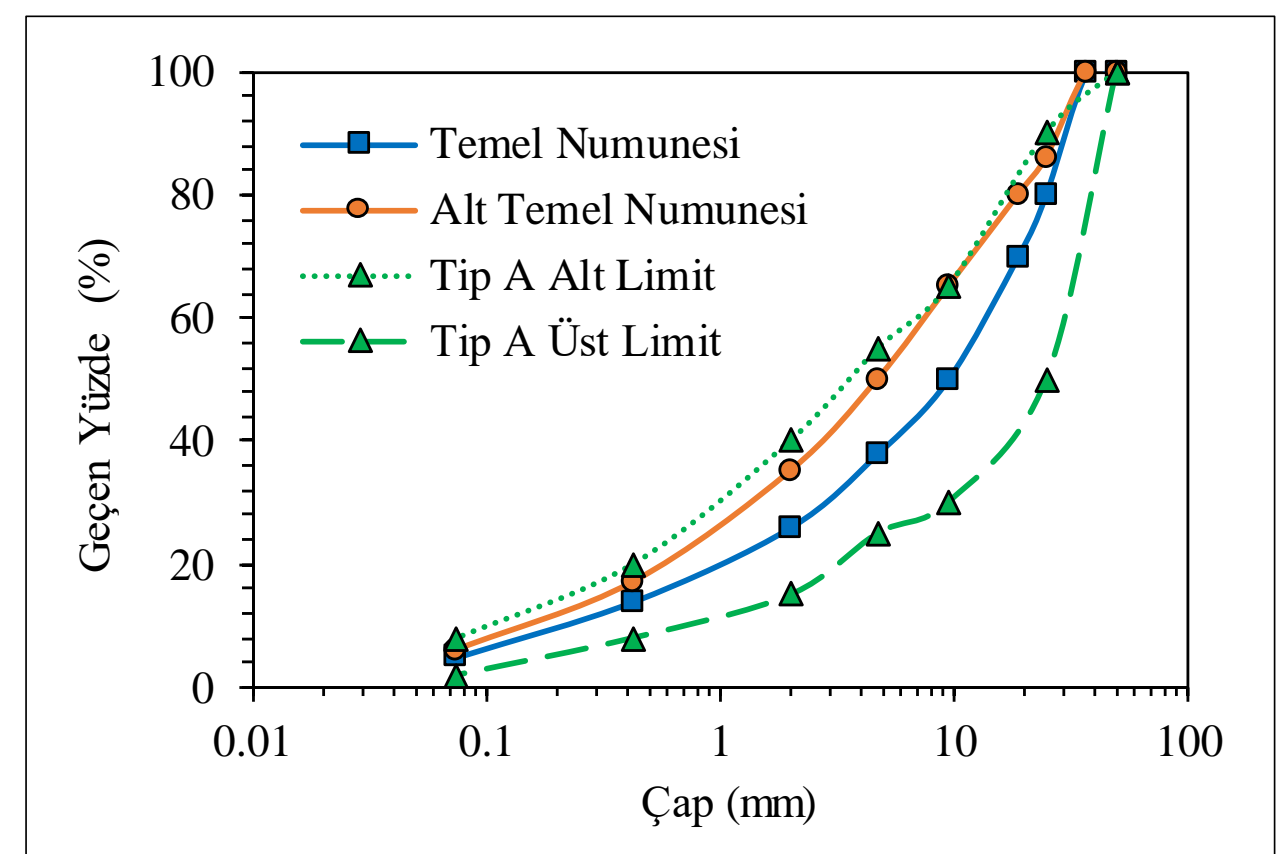

Şekil 1. Temel ve alt temel numuneleri için AASHTO [21] sınır değerleri dikkate alınarak hazırlanan dane çapı dağılımları 
Tablo 1. Hazırlanan temel ve alt temel numunelerinin geoteknik özellikleri

\begin{tabular}{|c|c|c|}
\hline \multirow{2}{*}{ Özellikler } & \multicolumn{2}{|c|}{ Malzeme } \\
\hline & Alt Temel & Temel \\
\hline \multicolumn{3}{|l|}{ Dane Çapı Dă̆ılımı } \\
\hline AASHTO & A-1-a & A-1-a \\
\hline Çakıl (\%) & 50 & 62 \\
\hline Kum $(\%)$ & 44 & 33 \\
\hline İnce Dane Oranı (\%) & 6 & 5 \\
\hline \multicolumn{3}{|l|}{ Sıkıştırma } \\
\hline$\gamma_{\mathrm{k} \text { maks }- \text { standart }}\left(\mathrm{kN} / \mathrm{m}^{3}\right)$ & 19.40 & 20.10 \\
\hline $\mathrm{w}_{\text {opt-standart }}(\%)$ & 11 & 10 \\
\hline$\gamma_{\mathrm{k} \text { maks-modifiye }}\left(\mathrm{kN} / \mathrm{m}^{3}\right)$ & 19.80 & 20.50 \\
\hline $\mathrm{w}_{\text {opt-modifiye }}(\%)$ & 8 & 7 \\
\hline \multicolumn{3}{|c|}{ Permeabilite Katsayısı $(\mathrm{cm} / \mathrm{s})$} \\
\hline $\mathrm{i}: 1$ & $5.50 \times 10^{-5}$ & $5.86 \times 10^{-5}$ \\
\hline i:5 & $5.60 \times 10^{-5}$ & $6.42 \times 10^{-5}$ \\
\hline i:7 & $5.45 \times 10^{-5}$ & $5.83 \times 10^{-5}$ \\
\hline i:9 & $5.53 \times 10^{-5}$ & $5.54 \times 10^{-5}$ \\
\hline $\mathrm{i}: 13$ & $5.98 \times 10^{-5}$ & $5.69 \times 10^{-5}$ \\
\hline Ortalama & $5.64 \times 10^{-5}$ & $5.87 \times 10^{-5}$ \\
\hline \multicolumn{3}{|l|}{ Mukavemet } \\
\hline$\phi\left({ }^{\circ}\right)$ & 32 & 48 \\
\hline $\mathrm{c}(\mathrm{kPa})$ & 28 & 10 \\
\hline Islak CBR (\%) & 121 & 133 \\
\hline Kuru CBR (\%) & 106 & 109 \\
\hline
\end{tabular}

\subsection{Esneklik Modülü ve Kalıcı Deformasyon Deneyleri}

Esneklik modülü ve kalıcı deformasyon deneyleri ile belirlenen esneklik özellikleri, esnek yol kaplama performansını etkileyen önemli faktörler arasında yer almaktadır. Numunelerin esneklik modülleri, AASHTO T-307 [22] 'ye göre tekrarlı üç eksenli yükleme ile belirlenmiştir. Bu çalışmada hazırlanan temel ve alt temel numunelerinin No. 10 ve No. 200 eleklerden geçen malzeme yüzdeleri sirasiyla $\% 70$ ve $\% 20$ 'den ve plastisite indisi \%10'dan az olduğu için yukarıda belirtilen ilgili deney standardına göre, Tip-1 olarak sınıflandırılmıştır. Bu nedenle bu malzemeler, ilgili standartta önerildiği gibi $152 \mathrm{~mm}$ çapında ve $305 \mathrm{~mm}$ yüksekliğinde bölünmüş bir kalıpta sıkıştırılarak deney numuneleri hazırlanmıştır. Esneklik modülünü belirlemek için AASHTO T-307 [22]'de tanımlanan sayıda ve gerilme değerlerinde 0.1 saniye yükleme süresi ve 0.9 saniye dinlenme süresine sahip haversine şeklindeki yükler hazırlanan temel ve alt temel numunelerine uygulanmıştır. Uygulanan çevre basınc1 ve deviatör gerilme değerleri yük tekrar sayıları ile birlikte her bir yükleme çevrimi için Tablo 2'de verilmiştir. Numunelerin hazırlanmasında kullanılan otomatik sıkıştırma ve esneklik modülü deney sistemi Şekil 2'de gösterilmiştir.

Esneklik modülü, uygulanan deviatör gerilmenin geri kazanılan deformasyona oranı $\left(\sigma_{d} / \varepsilon_{\mathrm{r}}\right)$ olarak hesaplanmaktadır. İstenilen çevre basıncı ve deviatör gerilme altında numunelerin esneklik modülünü tahmin etmek için literatürde önerilmiş birçok model bulunmaktadır. Bu çalışmada denklemleri sırasıyla Eş. (1), (2) ve (3)'te verilen, Hicks ve Monismith [23] tarafından önerilen Üssel model, Uzan [24] tarafindan önerilen Uzan model ve Mekanik-Ampirik Kaplama Tasarımı NCHRP 137A'da [25] belirtilen MEPD model temel ve alt temel numunelerinin doğrusal olmayan davranışını tahmin etmek için kullanılmıştır.

$$
\begin{aligned}
& \text { Üssel Model: } M_{R}=k_{1} \theta^{k_{2}} \\
& \text { Uzan Model: } M_{R}=k_{1} P_{a}\left(\theta / P_{a}\right)^{k_{2}}\left(\sigma_{d} / P_{a}\right)^{k_{3}} \\
& \text { MEPD Model: } M_{R}=k_{1} P_{a}\left(\theta / P_{a}\right)^{k_{2}}\left(\tau_{\text {oct }} / P_{a}+1\right)^{k_{3}}
\end{aligned}
$$


Burada; $\mathrm{M}_{\mathrm{R}}$ esneklik modülü, $\mathrm{k}_{1}, \mathrm{k}_{2}, \mathrm{k}_{3}$ laboratuvar deney sonuçları kullanılarak belirlenen en uygun model sabitleri, $\sigma_{d}$ deviatör gerilme ve $\mathrm{P}_{\mathrm{a}}$ atmosferik basınçtır. Sırasıyla toplam gerilme $(\theta)$ ve oktahedral kayma gerilmesini ( $\left.\tau_{\text {oct }}\right) \sigma_{1}, \sigma_{2}$ ve $\sigma_{3}$ asal gerilmeler cinsinden tanımlayan denklemler Eş. (4) ve Eş. (5)'te verilmiştir. Ayrıca, NCHRP raporu 01-28A'da [26] önerildiği gibi, $\theta=208 \mathrm{kPa}$ ve $\tau_{\text {oct }}=48.6 \mathrm{kPa}$ için Özet Esneklik Modülü (ÖEM) değerleri hesaplanmıştır.

$$
\begin{aligned}
& \theta=\sigma_{1}+\sigma_{2}+\sigma_{3} \\
& \tau_{\mathrm{oct}}=\frac{1}{3} \sqrt{\left(\sigma_{1}-\sigma_{2}\right)^{2}+\left(\sigma_{1}-\sigma_{3}\right)^{2}+\left(\sigma_{2}-\sigma_{3}\right)^{2}}
\end{aligned}
$$

Tablo 2. Tip 1 malzemeler için uygulanan yük çevrimleri [22]

\begin{tabular}{cccc}
\hline $\begin{array}{c}\text { Yük Çevrim } \\
\text { Sayısı }\end{array}$ & $\begin{array}{c}\text { Çevre Basıncı, } \\
\sigma_{3}(\mathrm{kPa})\end{array}$ & $\begin{array}{c}\text { Maks. Deviatör } \\
\text { Gerilme } \\
\sigma_{\mathrm{d} \text {,maks }}(\mathrm{kPa})\end{array}$ & $\begin{array}{c}\text { Yük Tekrar } \\
\text { Sayıs1 }\end{array}$ \\
\hline Başlangıç & 103.4 & 103.4 & 500 \\
1 & 20.7 & 20.7 & 100 \\
2 & 20.7 & 41.4 & 100 \\
3 & 20.7 & 62.1 & 100 \\
4 & 34.5 & 34.5 & 100 \\
5 & 34.5 & 68.9 & 100 \\
6 & 34.5 & 103.4 & 100 \\
7 & 68.9 & 68.9 & 100 \\
8 & 68.9 & 137.9 & 100 \\
9 & 68.9 & 206.8 & 100 \\
10 & 103.4 & 68.9 & 100 \\
11 & 103.4 & 103.4 & 100 \\
12 & 103.4 & 206.8 & 100 \\
13 & 137.9 & 103.4 & 100 \\
14 & 137.9 & 137.9 & 100 \\
15 & 137.9 & 275.8 & 100 \\
\hline
\end{tabular}
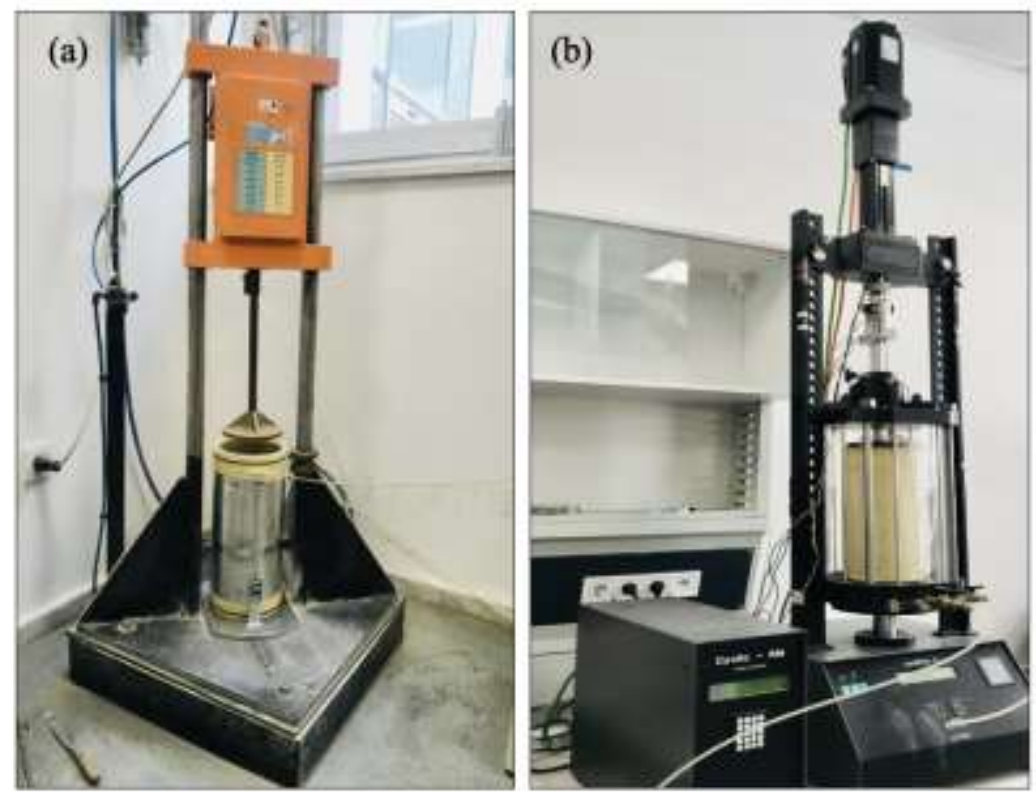

Şekil 2. (a) Numunelerin esneklik modülü deneyi için hazırlanması (b) Esneklik Modülü Deney Düzeneği

Esneklik Modülü, tekrarlı yüklemeye maruz kalan kaba daneli dolgu malzemelerinin uzun dönem performansını tam olarak değerlendirmek için yeterli olmayıp, plastik deformasyon deney sonuçları ile birlikte değerlendirilmesi yararlı olmaktadır [27]. Bu nedenle numuneler, tekerlek izini 
karakterize etmek için plastik deformasyon deneylerine tabi tutulmuş ve sonuçlar esneklik modülü deney sonuçları ile birlikte değerlendirilmiştir. NCHRP raporu 01-28A [26] 'da belirtildiği gibi, esneklik modülü deneyi ile aynı başlangıç yüklemesi ile başlayan ve $34.5 \mathrm{kPa}$ çevre basıncına $\left(\sigma_{3}\right), 206.8 \mathrm{kPa}$ deviatör gerilmeye $\left(\sigma_{\mathrm{d}}\right)$ sahip yükün 10000 (onbin) kez uygulanması ile devam eden plastik deformasyon deneyi hem temel hem de alt temel numunelerine uygulanmıştır.

\subsection{Esneklik Modülü ve Kalıcı Deformasyon Deney Sonuçları}

Bu çalışma kapsamında, \%100 GDBA ile hazırlanan temel ve alt temel numunelerin esneklik özellikleri, esneklik modülü ve plastik deformasyon deneyleri ile belirlenmiştir. Esneklik modülü değerleri, her yükleme serisindeki son 5 yük tekrarı için deviatör gerilmesinin $\left(\sigma_{\mathrm{d}}\right)$ elastik gerilmeye $\left(\varepsilon_{\mathrm{r}}\right)$ oranı olarak hesaplanmıştır. Esneklik modülünün $\left(\mathrm{M}_{\mathrm{R}}\right)$ toplam gerilme $(\theta)$ ile değişimi Şekil 3 'te gösterilmiştir.

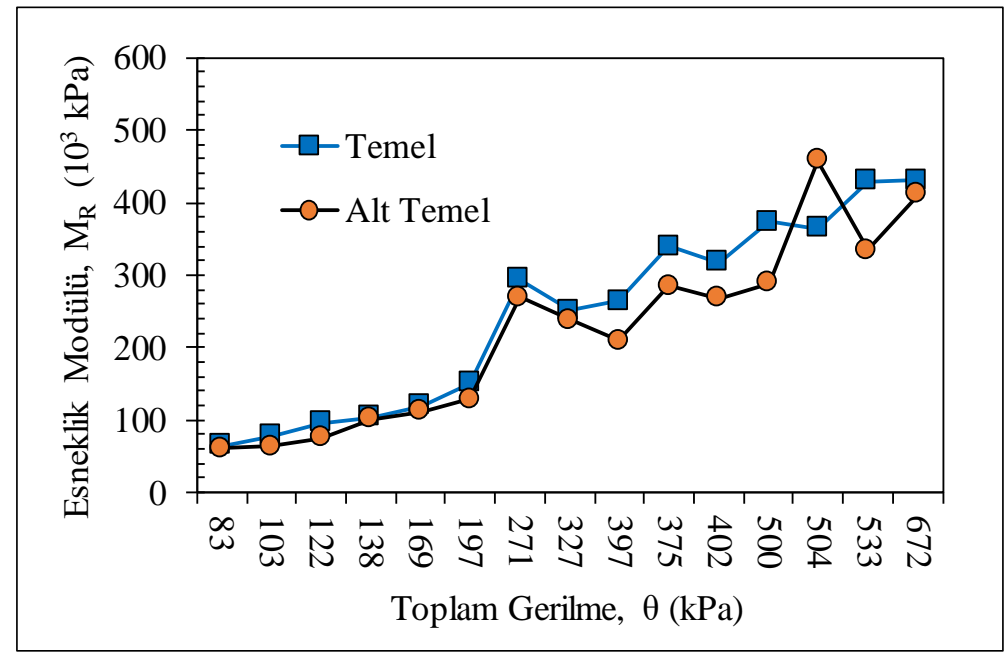

Şekil 3. Farklı toplam gerilmelerinde temel ve alt temel numunelerinin esneklik modülü

Verilen şekilden, temel ve alt temel numuneleri için esneklik modülü $\mathrm{M}_{\mathrm{R}}$ değerlerinin sırasıyla 65-430 MPa ve 60-410 MPa aralığında değiştiği görülmektedir. Bu çalışmada elde edilen toplam gerilme- $M_{R}$ ilişkisi önceki çalışmalarda elde edilenlerle uyumlu olup [28, 29], numunelerin $M_{R}$ değerleri arasındaki fark, dene şekli, dane çapı dağılımı ve su içeriği gibi faktörlerle açıklanabilmektedir [30].

Kaba daneli malzemelerin uzun süreli davranışı ile esneklik modülü değeri ile ilişkisi göz önüne alındığında, doğru tahmin edilen $\mathrm{M}_{\mathrm{R}}$ değerlerinin kullanılması tasarım sürecini ve nihayetinde kaplama performansını etkilediği açıktır. Esneklik modülünü tahmin eden üç farklı doğrusal olmayan model uygulandıktan sonra en uygun model belirlenmiş ve çalışmanın sayısal analiz aşamasında belirlenen modelden elde edilen parametreler kullanılmıştır.
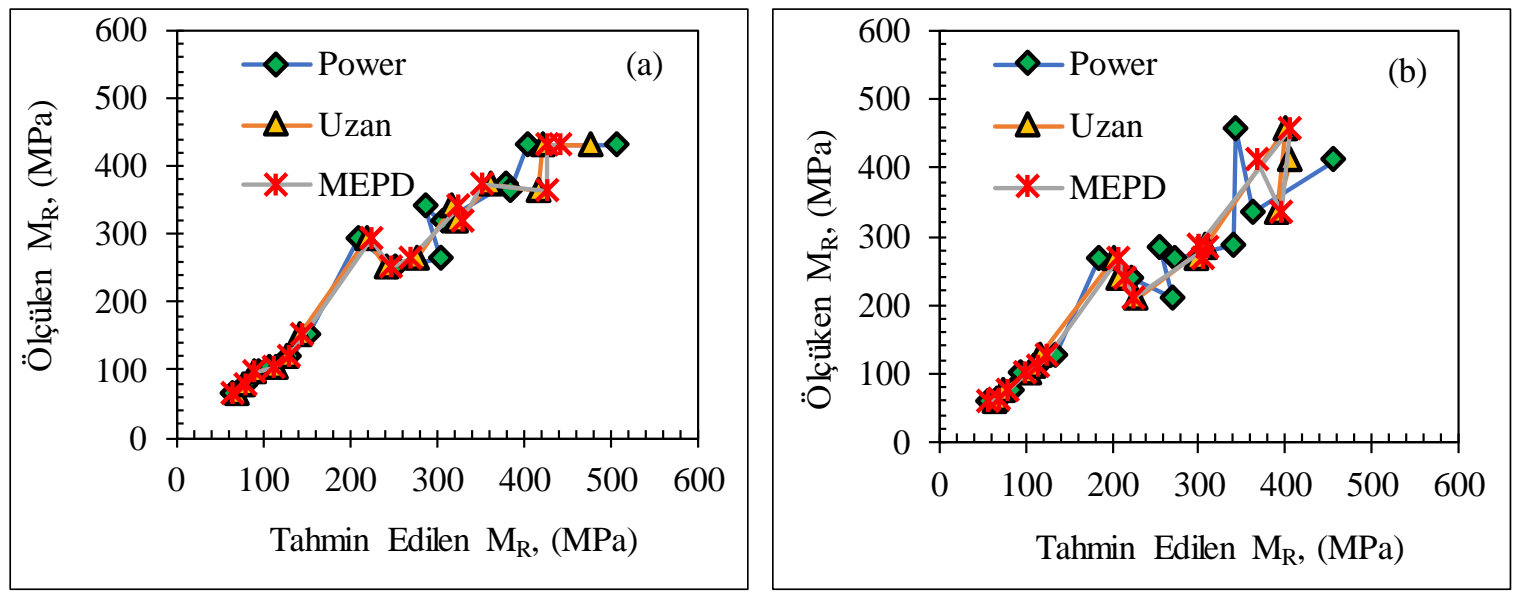

Şekil 4. (a) temel ve (b) alt temel numuneleri için ölçülen ve tahmin edilen esneklik modülleri 
Hazırlanan numunelerin deney sırasında ölçülen esnek modülüne karşılık üç farklı model ile tahmin edilen esneklik modülü değerleri Şekil 4'te göstermektedir. Her modelin özet esneklik modülü (ÖEM) ve korelasyon katsayısı $\left(\mathrm{R}^{2}\right)$ değerleri ise Tablo 3 'te özetlenmiştir. Önerilen her üç modelin de temel ve alt temel numuneleri için yüksek korelasyon katsayısına sahip olduğu görülmektedir. Ancak esneklik modülü deneylerinden ölçülen $M_{R}$ değerlerinden en az sapma her iki numunede de MEPD modelinde elde edildiği için trafik yükü altında uygulanan sayısal analizlerde $M_{R}$ değerinin derinlikle değişiminde bu model parametreleri kullanılmıştır.

Tablo 3. Temel ve alt temel numuneleri için elde edilen model parametreleri

\begin{tabular}{ccccccccccc}
\hline \multirow{2}{*}{ Model } & \multicolumn{3}{c}{ Alt Temel } \\
\cline { 2 - 11 } & $\mathrm{k}_{1}$ & $\mathrm{k}_{2}$ & $\mathrm{k}_{3}$ & $\mathrm{R}^{2}$ & ÖEM & $\mathrm{k}_{1}$ & $\mathrm{k}_{2}$ & $\mathrm{k}_{3}$ & $\mathrm{R}^{2}$ & ÖEM \\
\hline Üssel & 702.9 & 0.99 & - & 0.86 & 142.24 & 931.9 & 0.97 & - & 0.93 & 163.78 \\
Uzan & 577.4 & 1.28 & -0.33 & 0.94 & 120.90 & 850.1 & 1.12 & -0.17 & 0.96 & 150.91 \\
MEPD & 782.2 & 1.23 & -1.03 & 0.93 & 128.74 & 878.6 & 1.12 & -0.65 & 0.96 & 154.35 \\
\hline
\end{tabular}

Plastik deformasyon deneyinde temel ve alt temel numuneleri için 10000 yük tekrarına kadar belirtilen tekrarlı gerilme genliklerinde plastik deformasyon değerleri Şekil 5 'te gösterilmiştir. Şekilden de görülebileceği üzere nihai durumda numunelerde oluşan plastik deformasyonlar $\% 0.08<\varepsilon_{\mathrm{p}}<\% 0.10$ aralığında kalmıştır. Plastik deformasyon deney sonuçları, alt temel numunelerinin temel numunelerine kıyasla daha yüksek plastik deformasyon değerlerine sahip olduğunu göstermektedir. Bu durum temel numunelerinin alt temel numunelerine göre sahip olduğu daha iyi parçacık kenetlenmesi ve daneler arası daha yüksek temas alanı ile açıklanabilmektedir [31].

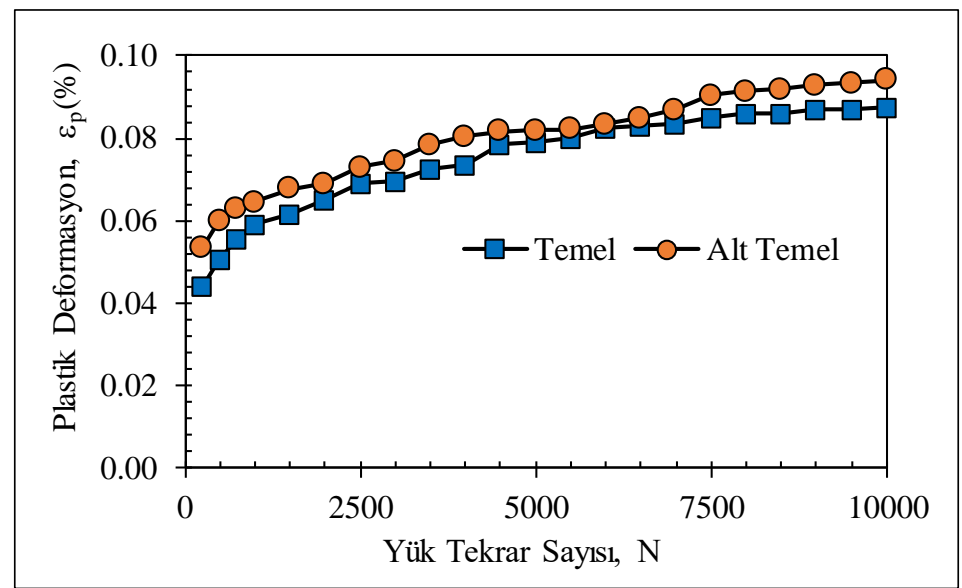

Şekil 5. Temel ve alt temel numunelerinin plastik deformasyon değerlerinin yük tekrar sayısı ile değişimi

\subsection{Sayısal Analizler}

Sayısal analizlerde, temel ve alt temel tabakalarında GDBA kullanılacak esnek bir yol kaplamanın mekanik davranışı çoklu tekerlek yüklerinin dinamik olarak uygulandığı üç boyutlu modeller kurularak sonlu farklar yöntemiyle incelenmiştir. Temel ve alt temel tabakalarının doğrusal olmayan davranış1 dikkate alınarak, deneysel olarak esneklik modülleri tespit edilen malzemelerin tekerlek yükleri altındaki birikmiş plastik deformasyon değerleri diğer bir deyişle tekerlek izleri ile kaplamada ağır tekerlek yüküne maruz kaldığında aracın farklı eksenlerinde oluşacak deformasyonlar arasındaki en büyük sapma değerleri bitümlü sıcak karışım tabakasından oluşan üst kaplama kalınlığına bağlı olarak araştırılmıştır.

Bu bölümde özellikle sayısal analizlerde göz ardı edilen birbirine yakın mesafede birden fazla yüklemeye maruz kalan yol tabakalarında zemin gerilmelerinde oluşan girişimin etkileri incelenmiştir. Ayrıca hareketli taşıt yüklerinin dinamik olarak etkitilerek incelenmesi çalışmanın literatüre katkı olarak değerlendirilmektedir. Üst üste gelen gerilmelere karşı esnek kaplama tabakalarının mekanik 
performans1 ve dinamik yük altında kaplamadaki asal gerilmelerin dönüşü ancak 3 boyutlu analiz ile incelenebilir. $\mathrm{Bu}$ tür analizler, doğrusal olmayan zemin özellikleri ve gelişmiş sınır koşulları tanımlanarak sahayla uyumlu sonuçlar sağlamaktadır. Böylelikle, tasarım sürecinde göz ardı edilebilen genişlik, şev açısı gibi yol kesiti geometrisinden, tekil yük ve tandem gibi çoklu yükleme şeklinden, statik ve dinamik yükleme durumundan kaynaklanan etkilerin dikkate alınmasını sağlamaktadır.

$\mathrm{Bu}$ çalışmada üç boyutlu esnek yol kaplama modelinin ağır bir vasıtanın geçişi sırasında etkisinde kalacağı yükleme durumu, tek aksa sahip ön teker takımı ve tandem durumundaki çift akstan ve 4 ila 8 adet tekerden oluşan çoklu yüklemenin yapıldığı arka bölümden oluşan bir kamyon yükü olarak tanımlanmıştır. Yapılan sayısal analizlerin temel amacı, doğrusal olmayan zemin davranışını dikkate alarak, çoklu tekerlek yükleri altında üst üste binen gerilme bölgelerinde oluşacak maksimum plastik deformasyon değerlerini tahmin etmektir. Çalışmanın sayısal modellerinde, esnek yol kaplamasındaki doğal zemin tabakası yumuşak ila orta sert kumlu siltli kil olarak alınmıştır. Ek olarak, Bitümlü Sıcak Karışım (BSK) özellikleri, TS 3720 "Bitümlü Kaplama Karışımlarının Hesap Esasları" standardına göre Marshall Metodu [32] dikkate alınarak seçilmiştir. Bu analizlerde, esneklik modüllerinin derinlikle değişimi, deneysel sonuçlara en yakın esneklik modülü değerlerinin elde edildiği MEPD modeli ile belirlenmiştir. 3 boyutlu (3B) modelin geometrik özellikleri, esnek kaplama tabakalarının fiziksel ve mekanik özellikleri, modelin sınır koşulları ve uygulanan dinamik yüklemenin özellikleri aşağıda verilmektedir.

\subsection{Boyutlu Yol Modeli ve Sınır Koşulları}

Modellere ait analizler, açık sonlu fark şeması ile çalışan ve FLAC3D yazılımında doğrusal olmayan yöntemle gerçekleştirilmiştir. Sonlu farklar yöntemi düzensiz geometrilerin modellenmesinde esneklik sağladığından ve zaman tanım alanında dinamik analizlere uygunluğu nedeniyle tercih edilmiştir. Dahas1, tamamen doğrusal olmayan yöntem, önceden belirlenmiş herhangi bir doğrusal olmayan malzeme bünye bağıntısının kullanımına imkân tanımakta ve plastik akma uygun şekilde modellenebilmektedir.

Sayısal analizler, ağır trafik yükleri altında geri dönüştürülmüş malzemelerle tasarlanan yol yapısının performansını inceleme amacıyla yapılmıştır. Yol kaplama enkesiti, bitümlü sıcak karışım altında yer alan \%100 GDBA ile hazırlanan temel ve alt temel tabakası ile alt temel tabakası altında yer alan doğal zemin olmak üzere 4 tabakadan oluşmaktadır. Ayrıca, bitümlü sıcak karışım BSK tabakası kalınlığının esnek yol kaplamanın mekanik performansı üzerindeki etkilerini araştırmak için, sayısal analizler BSK'nın $0.05 \mathrm{~m}$ ve $0.10 \mathrm{~m}$ olduğu durumlar için ayrı ayrı gerçekleştirilmiştir. Temel ve alt temel tabakaları sırasıyla $0.30 \mathrm{~m}$ ve $0.65 \mathrm{~m}$ kalınlığında tanımlanmıştır. Doğal zemin tabakası yarı sonsuz uzay olarak devam etmektedir. Modellenen kaplamanın genişliği (L), yüksekliği (H) ve eğimi sırasıyla $7.0 \mathrm{~m}, 1.0 \mathrm{~m}$ ve $45^{\circ}$ olarak alınmıştır. Model uzunluğu, standart bir kamyonun boyutlarına göre yeterince uzun olarak seçilmiştir. Oluşturulan 3B esnek yol kaplama modeli 236640 adet tetrahedral eleman ile ayrıklaştırılarak sonlu fark ağı oluşturulmuştur. Modellerde, sınır bölgeleri yakınındaki düzensiz yük ve gerilme konsantrasyonlarını gidermek için gelişmiş sınır koşulları uygulanmıştır. Kaplama modelinin şematik bir temsili Şekil 6'da gösterilmektedir.

Alt sınırda sessiz sınır (quiet boundry) şeması uygulanmış, yanal sınırlar için, yansıtıcı olmayan serbest alan sınırları, viskoz sönümleyiciler yardımıyla tanımlanan ana ızgarayı serbest alan ızgarasına bağlamak için kullanılmıştır. Her iki koşul, Eş. (6), (7), (8) ve (9)'da verilen kayma ve normal gerilmelerin viskoz karşıtlarını üretmek için tanımlanarak, sahada var olan gerilme durumuna en yakın benzerlikte model kurulmuştur.

$$
\begin{aligned}
& \mathrm{t}_{\mathrm{n}}=-\rho \mathrm{C}_{\mathrm{p}} \mathrm{V}_{\mathrm{n}} \\
& \mathrm{t}_{\mathrm{n}}=-\rho \mathrm{C}_{\mathrm{s}} \mathrm{V}_{\mathrm{s}} \\
& \mathrm{F}_{\mathrm{x}}=-\rho \mathrm{C}_{\mathrm{p}}\left(\mathrm{v}_{x}^{m}-\mathrm{v}_{x}^{f f}\right) A+\mathrm{F}_{x}^{f f} \\
& \mathrm{~F}_{\mathrm{y}}=-\rho \mathrm{C}_{\mathrm{s}}\left(\mathrm{v}_{y}^{m}-\mathrm{v}_{y}^{f f}\right) A+\mathrm{F}_{y}^{f f} \mathrm{q} 2
\end{aligned}
$$


Burada, sirasıyla, $t_{n}$ ve $t_{s}$ türetilen karşıt normal ve kayma gerilmeleri, $\rho$ kütle yoğunluğu, $C_{p} v e$ $\mathrm{C}_{\mathrm{s}}$ sırasıyla basınç (P) ve kayma (S) dalga hızları ve $\mathrm{v}_{\mathrm{n}}$ ve $\mathrm{v}_{\mathrm{s}}$ malzeme ortam hızının normal ve kayma bileşenleridir. $F_{x}, F_{y}$, $x$ ve y doğrultularındaki kuvvetleri, A, serbest sınır serbest bölge (Free Field) ağ üzerindeki dügüm noktalarının etkili alanıdır. $\mathrm{C}_{\mathrm{s}}$ ve $\mathrm{C}_{\mathrm{p}}$ yan sınırlara ulaşan $\mathrm{P}$ ve $\mathrm{S}$ dalgalarının hızlarıdır. $v_{\mathrm{x}}{ }^{\mathrm{m}}$ ve $\mathrm{v}_{\mathrm{y}}{ }^{\mathrm{m}}$ modeli oluşturan sonlu fark ağının yan sınırlarında bulunan düğüm noktalarının hızlarıdır. $\mathrm{v}_{\mathrm{x}}{ }^{\mathrm{ff}}$ ve $\mathrm{v}_{\mathrm{y}}{ }^{\mathrm{ff}}$, Serbest Bölge ağı üzerinde bulunan düğüm noktalarının hızlarıdır. $\mathrm{F}_{\mathrm{x}}{ }^{\mathrm{ff}}, \mathrm{F}_{\mathrm{y}}{ }^{\mathrm{ff}}$, yan sinırlar boyunca dügüm noktalarına serbest bölge ağındaki elemanlarda oluşan $\sigma_{\mathrm{xx}}{ }^{\mathrm{ff}}, \sigma_{\mathrm{xy}}{ }^{\mathrm{ff}}$ gerilmelerinden gelen kuvvetleri göstermektedir.

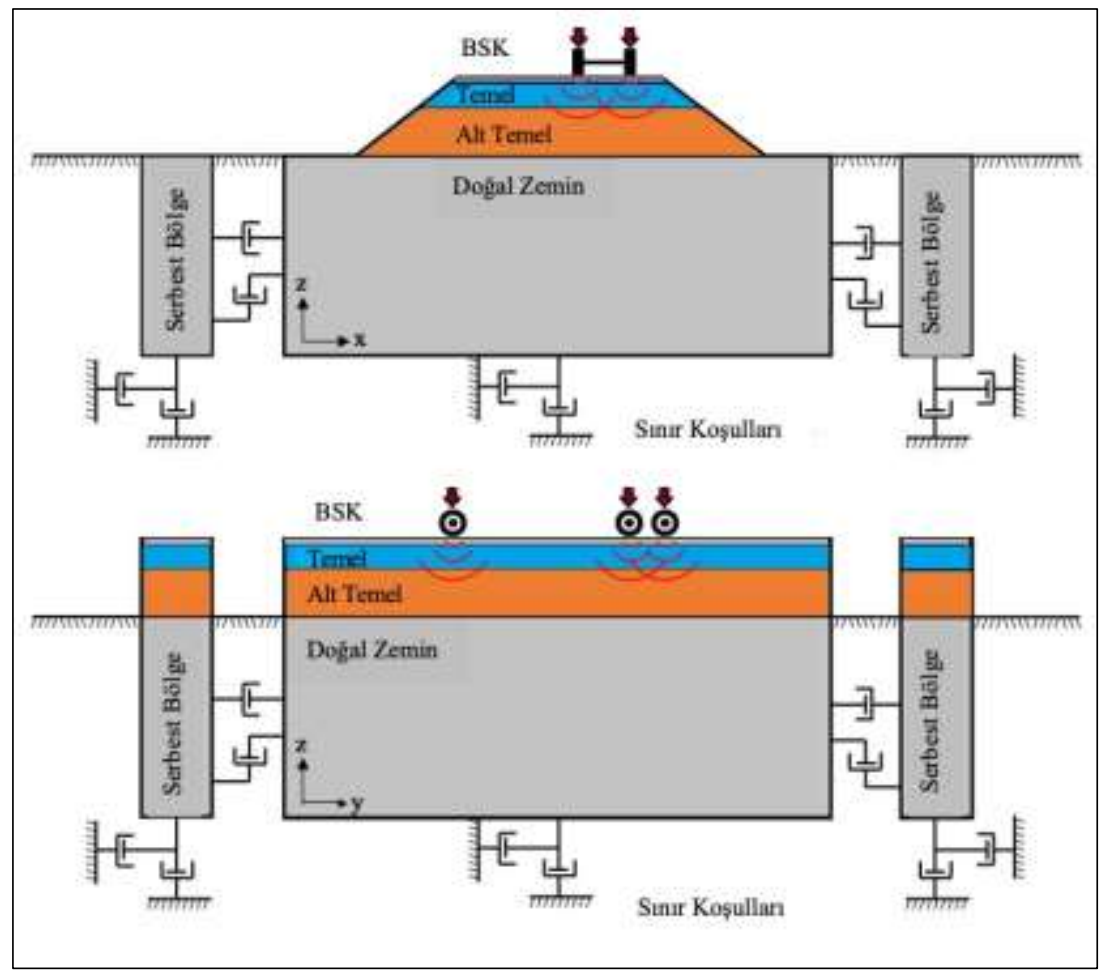

Şekil 6. 3 boyutlu yol modelinin geometrik özellikleri ve sınır koşulları.

İncelenen modellere ait ayrıklaştırılmış ortamın geometrik özellikleri ve ileri sınır koşullarıyla tanımlanan ilave eleman ağları Şekil 7'de görülmektedir. Ayrıca yüzeyde tanımlı BSK tabakası iki faklı kalınlık için Şekil 8'de verilmiştir.

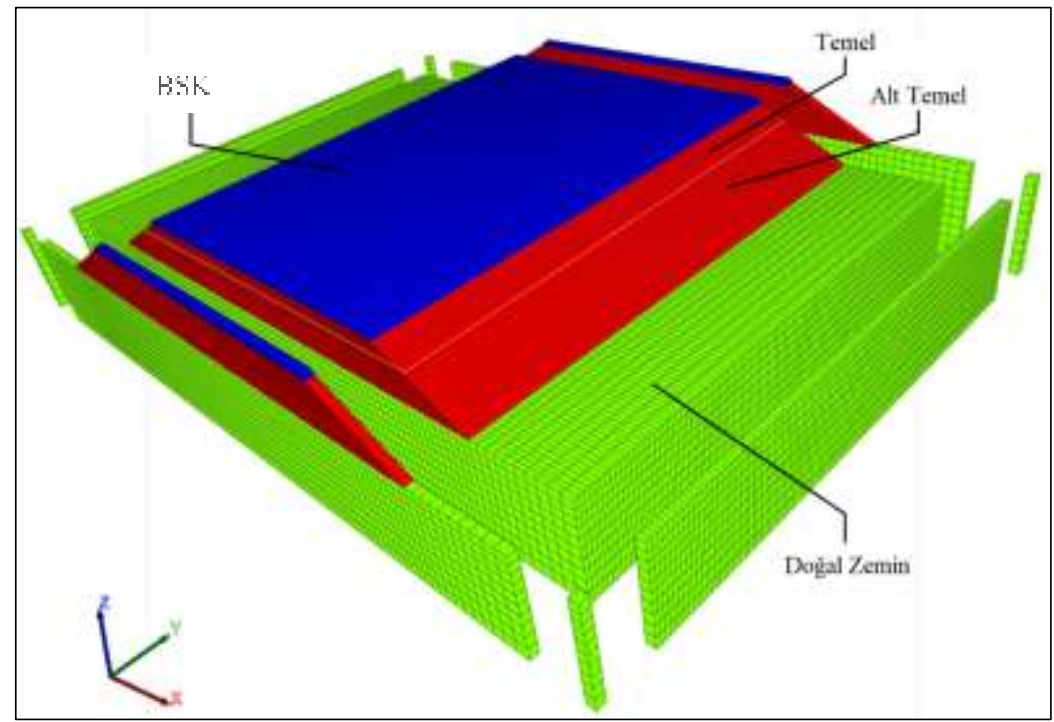

Şekil 7. Sayısal analiz için hazırlanan esnek yol kaplama enkesitinin 3 boyutlu modeli 


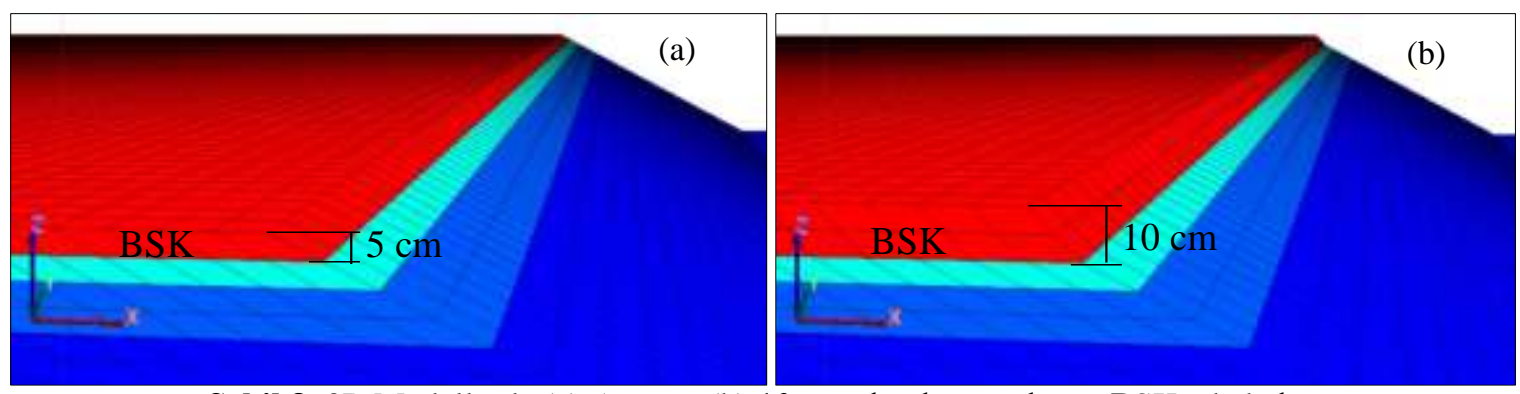

Şekil 8. 3B Modellerde (a) $5 \mathrm{~cm}$ ve (b) $10 \mathrm{~cm}$ olarak tanımlanan BSK tabakaları

\subsection{Malzeme Özellikleri ve Dinamik Taşıt Yükü}

Haversine fonksiyonu şeklindeki dinamik ağır bir trafik yükü BSK yüzeyine uygulandığında, yüksek gerilme seviyelerinde temel, alt temel ve doğal zemin tabakalarında biriken plastik deformasyon değerleri elasto-plastik Mohr-Coulomb modeli kullanılarak incelenmiştir. Daha düşük deformasyon seviyelerinde ise histeretik şeması ile kayma modülünün değişimi ve döngüsel sönümleme tanımlanmıştır. $\mathrm{Bu}$ durum çoklu ağır trafik yükleri altında GDBA'nın tamamen doğrusal olmayan davranışının model üzerindeki her nokta için araştırılmasını imkân sağlamıştır. BSK tabakasının malzeme özelliklerinin elastik olduğu varsayılmıştır. Sayısal analizlerde kullanılan $0.05 \mathrm{~m}$ ve $0.10 \mathrm{~m}$ BSK tabakasına sahip 2 esnek yol kaplama tabakalarının geoteknik özellikleri ve esneklik modülü değerlerinin derinlikle değişimi Şekil 9'da verilmiştir.

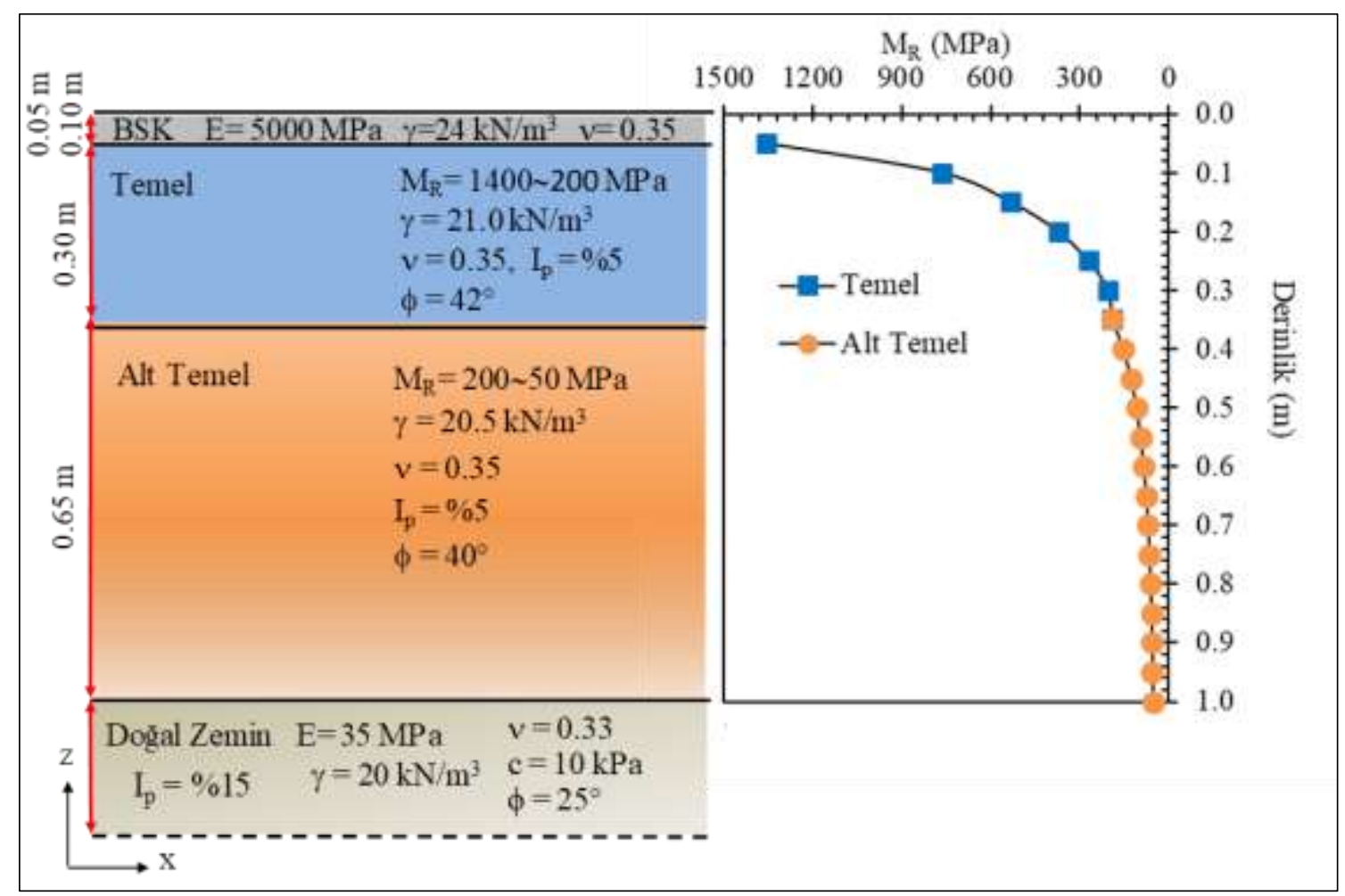

Şekil 9. $0.05 \mathrm{~m}$ ve $0.10 \mathrm{~cm}$ BSK tabakasına sahip esnek yol kaplama tabaklarının özellikleri ve esneklik modüllerinin derinlikle değişimi

Kullanılan malzemeler için tanımlanan histeretik eğriler, Ishibashi ve Zhang [33] tarafından önerilen korelasyonlar kullanılarak hazırlanmıştır. Azalım yöntemi, derinlikle değişen efektif gerilmelerdeki artışı dikkate alarak, plastisite indisine bağlı olarak değişmektedir. Bu nedenle, sayısal analizlerde zeminlerin homojen olmayan ve anizotrop yapısı dikkate alınmıştır. Yükleme yapılmadan önceki denge durumunda model kesitlerindeki normal zemin gerilmeleri Şekil 10'da gösterilmektedir. Yüzeydeki gerilmeler sıfırdan başlayarak modelin tabanında yaklaşık $60 \mathrm{kPa}$ ya ulaşmıştır. Ayrıca modelin düşey sınırlarında gerilme konturlarının paralel olduğu görülmüştür. Bu durum, modelin yatay 
boyutunun yeterli genişlikte seçildiğini göstermekte ve modelin başlangıç koşullarının doğrulandığını teyit etmektedir.

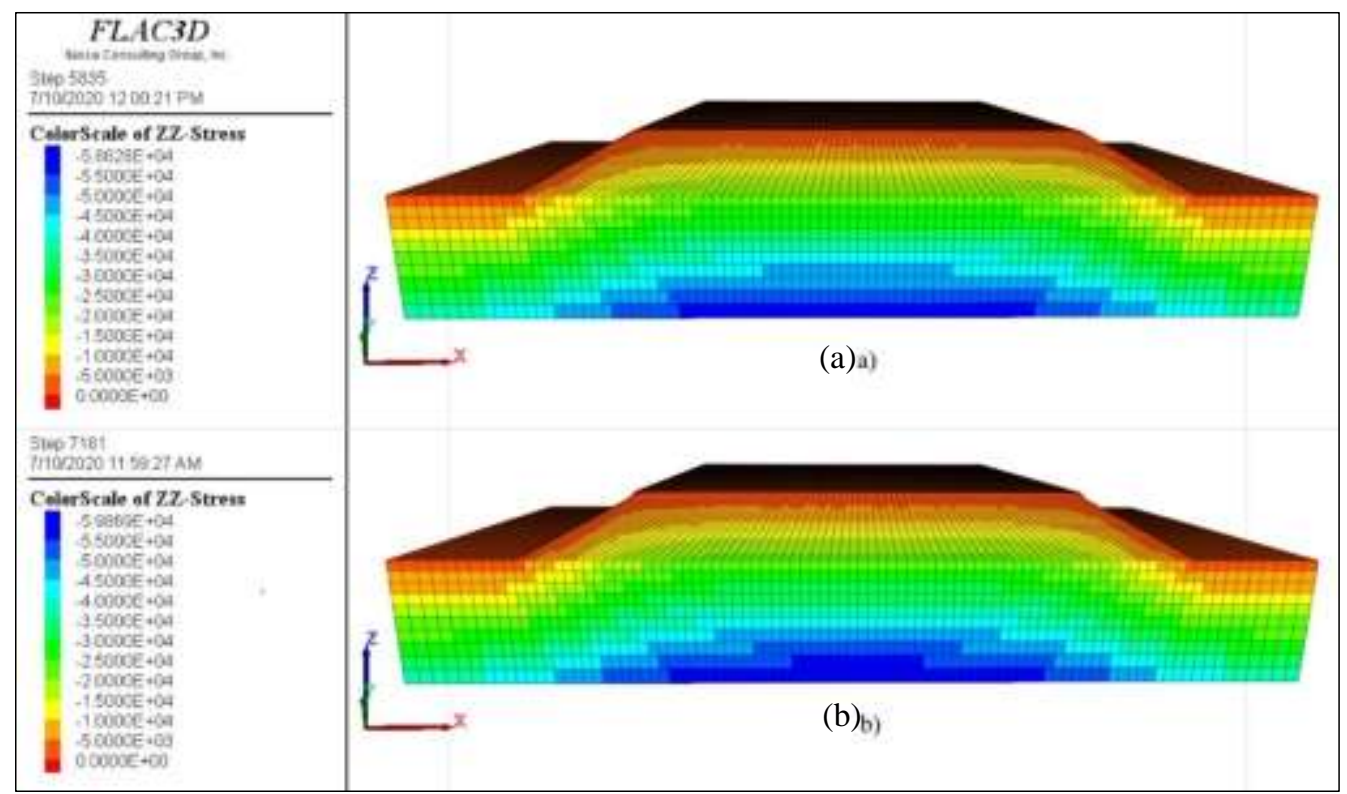

Şekil 10. Başlangıç denge durumunda esnek yol kaplama modellerindeki normal gerilme dağılışı (a) BSK kalınlığı $5 \mathrm{~cm}$ ve (b) BSK kalınlığ $10 \mathrm{~cm}$

Temel ve alt temel malzemelerinin ağır trafik yükleri altında davranışını araştırmak için farklı dingil özelliklerine sahip bir kamyon seçilmiştir. Tek ön dingil ve tandem şeklindeki arka dingillerin uyguladığı basınç yükü maksimum 1.0 MPa genlikli Haversine fonksiyonu şeklinde dinamik olarak etkitilmiştir. Her bir tekerleğin temas yüzeyi $0.20 \mathrm{~m} \times 0.20 \mathrm{~m}$ 'lik alandan oluşmaktadır. BSK'ya uygulanan dinamik yük, iki aşamadan oluşmaktadır. Bunlar, taşıt yükü ( 0.1 saniye) ve dinlenme süresi (0.9 saniye) olarak Şekil 9'da standart bir kamyon aks sistemi ile birlikte gösterilmektedir.

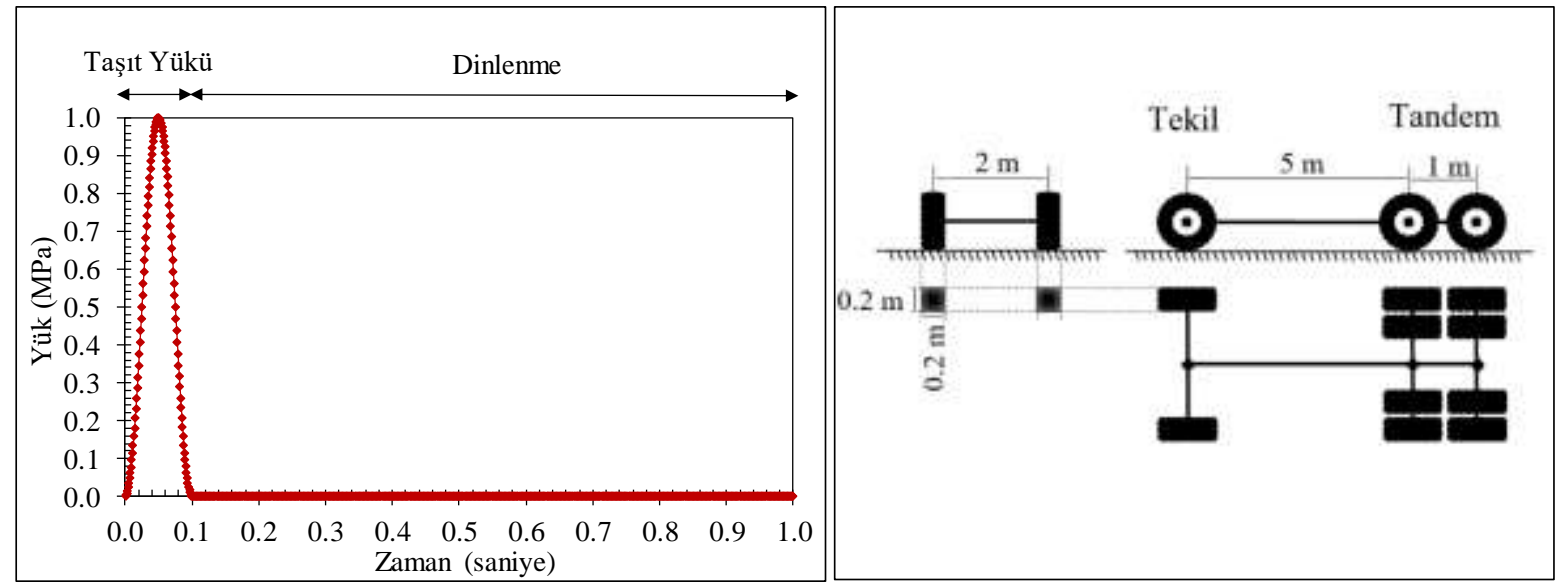

Şekil 11. Modellere uygulanan yükleme fonksiyonu ve taşıt yüklemesinin şematik gösterimi.

\subsection{Sayısal Analiz Sonuçları}

Sayısal analizlerde elde edilen sonuçlarla BSK kalınlığının üç boyutlu olarak modellenen esnek yol kaplamanın mekanik davranışına etkileri değerlendirilmiştir. Analizlerde BSK tabakasının $0.05 \mathrm{~m}$ olarak tanımlandığı modelde tandem yüklemesinin yapıldığ 1 taşıt arka tekerlerinin iz düşümünde $1 \mathrm{MPa}$ değerindeki teker yükleri altında model tabanında zemin gerilmelerinin $60 \mathrm{kPa}$ değerinden $100 \mathrm{kPa}$ değerine kadar çıktı̆̆ 1 ve zemin gerilmelerinin oluşturduğu girişim Şekil 12'de verilen yeşil bölümde görülmektedir. 


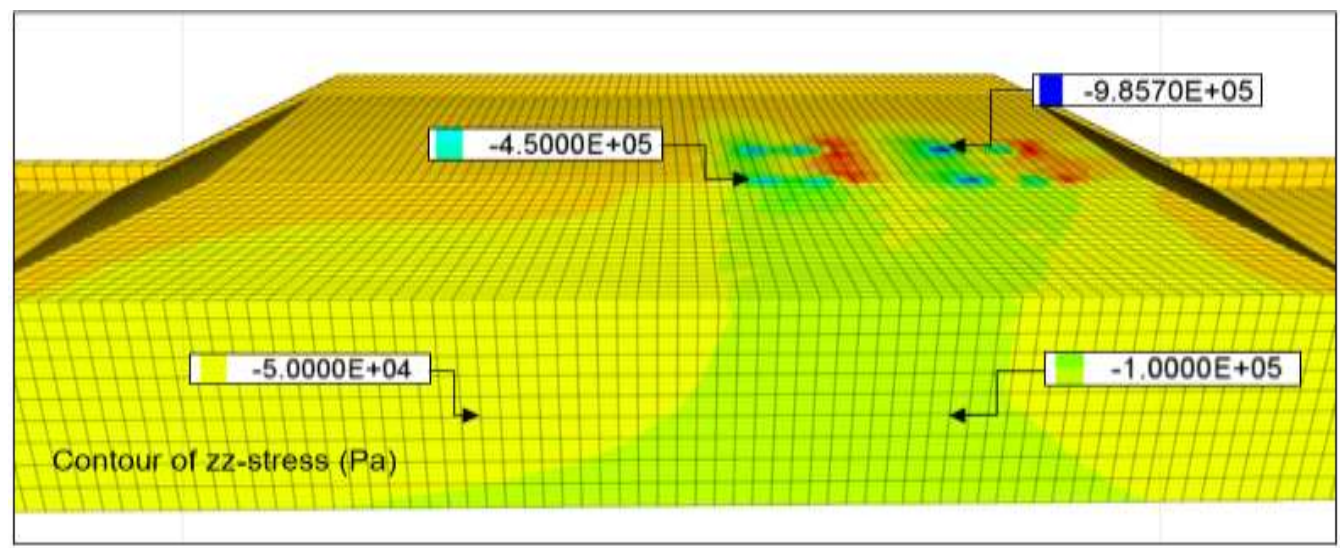

Şekil 12. Yüklemenin $\mathrm{t}=0.05 \mathrm{~s}$ anında tandem altında oluşan düşey gerilmeler

Şekil 13 (a) incelendiğinde esnek yol kaplama modelinde kaplama tabakasının $0.05 \mathrm{~cm}$ olduğu durumda merkeze yaklaştıkça teker altında oluşan deplasmanların tek akstan oluşan teker yükleri altında $1.5 \times 10^{-3} \mathrm{~m}$ seviyelerinden $2.75 \times 10^{-3} \mathrm{~m}$ değerlerine yükseldiği görülmektedir. Aynı şekilde tandem yükü altında arka bölümde $8 \times 10^{-3} \mathrm{~m}$ değerindeki deplasmanların yine merkeze doğru $11 \times 10^{-3} \mathrm{~m}$ değerine kadar çıktığ1 görülmektedir. Yüzeydeki deplasmanların esnek yol kaplama kesitinin orta bölümüne yakın olan A-A aksında ve kenar bölümdeki B-B aksında değişimini veren Şekil 13 (b) grafiğinde de bu fark açıç̧a görülmektedir. Bu durum eksenel simetrik veya düzlemsel deformasyon analizlerinde iki boyutlu modellerde yakalanamayan, elastik kaplama altındaki basınç dağılımı, yükleme sırasında asal gerilmelerin dönmesi ve şev kenarlarındaki düşük kayma gerilmeleri nedeniyle yol merkezine doğru daha yüksek deplasmanların meydana gelmesine neden olmuştur. Diğer yandan temel, alt temel ve doğal zemin tabakalarında oluşan deplasmanların ulaştığı değerler Şekil 13(c)'de verilmiştir.

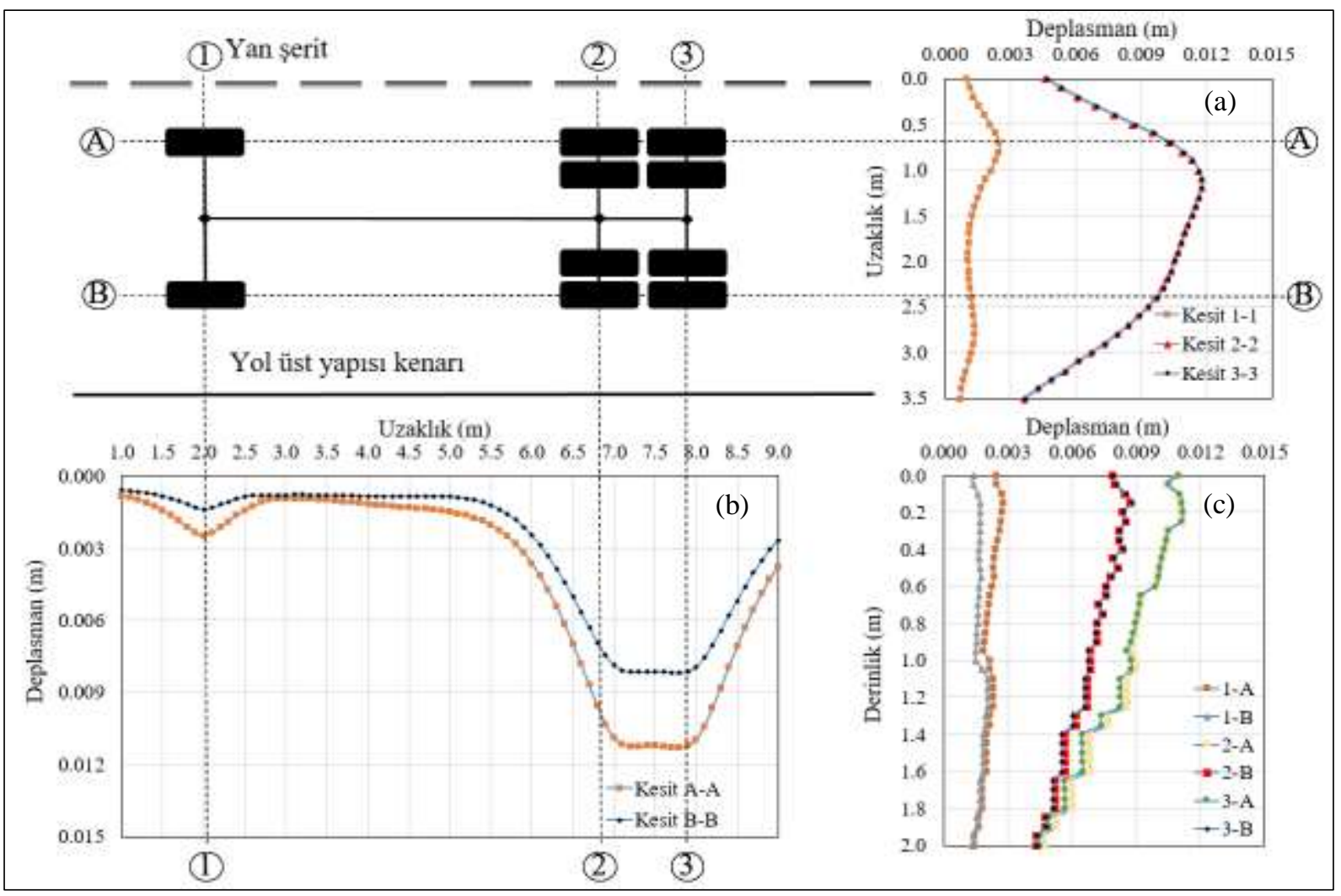

Şekil 13. $0.05 \mathrm{~m}$ BSA tabakasına sahip esnek yol kaplama modelinde kesitlerde dinamik taşıt yükü altında elde edilen deplasmanlar 
Yol yüzeyinde teşkil edilen kaplama kalınlığının 0.10 m tanımlandığı ikinci grup analizlerde dinamik taşıt yükü altında elde edilen maksimum deplasman değerleri Şekil 14(a), 14(b) ve 14(c) ile verilen grafiklerde sunulmuştur. Tandem yüklemesinin bulunduğu arka bölümdeki çoklu teker yüklerinin birbirine yakınlığı ve zeminde oluşan normal gerilmelerin girişimi nedeniyle 2-2 ve 3-3 akslarındaki deplasmanların ilk grup analiz sonuçlarına benzer şekilde daha yüksek olduğu görülmektedir. Ancak çarpıcı şekilde ilk grupta merkeze yakın konumdaki A-A aksı boyunca oluşan deplasman değerlerinin B-B aksındaki değerlere oldukça yaklaştığı görülmektedir. Bu durum ise yüzeyde oluşturulan elastik kaplama kalınlığının artışıyla yüzeye uygulanan taşıt yüklerinin alt tabakalara nispeten daha homojen aktarılmasıyla açıklanabilir. $5 \mathrm{~cm}$ kalınlığında kaplama ile oluşturulan modelde $11 \times 10^{-3} \mathrm{~m}$ değerindeki en büyük deplasman değerlerinin $7.8 \times 10^{-3} \mathrm{~m}$ değerlerine, tek aks ile yüklemenin yapıldığ 1 ön kısımda ise $2.75 \times 10^{-3} \mathrm{~m}$ değerinden $1.5 \times 10^{-3} \mathrm{~m}$ değerine düştüğü görülmektedir.

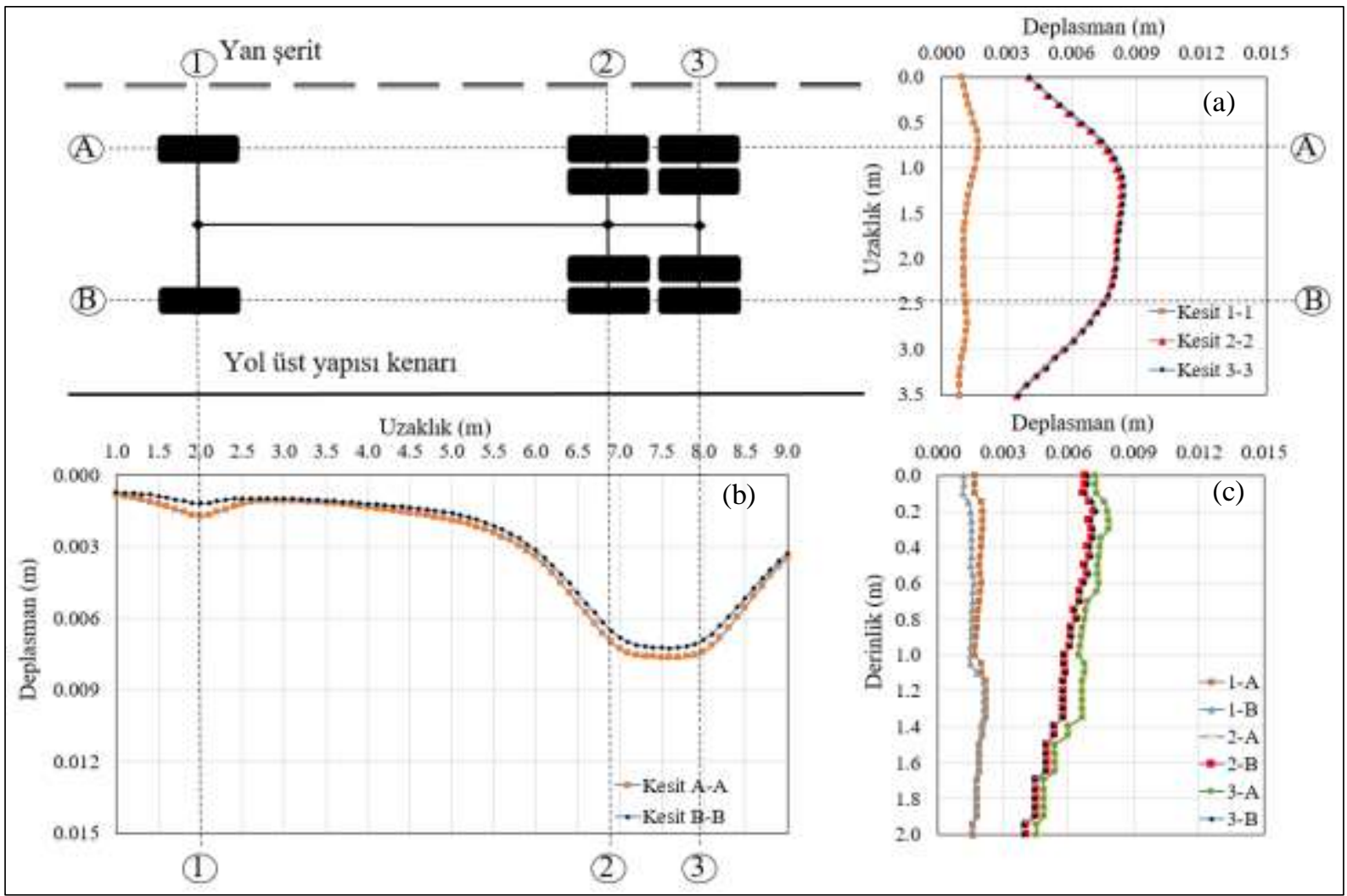

Şekil 14. $0.10 \mathrm{~m}$ BSA tabakasına sahip esnek yol kaplama modelinde kesitlerde dinamik taşıt yükü altında elde edilen deplasmanlar

Ayrıca çalışmada \%100 GDBA kullanılarak oluşturulan esnek kaplamanın mekanik davranışın yüzey oturmalarındaki etkilerinin araştırıldığı sayısal analizlerle tekerlekler altında tahmin edilen deplasman değerlerinin AASHTO Kaplama Yapıları Tasarımı Kılavuzu'na [21] ve NCHRP 1-37A [25] standartlarında belirtilen $11.51 \times 10^{-3} \mathrm{~m}$ ve $19.05 \times 10^{-3} \mathrm{~m}$ değerlerinden daha düşük olduğu sonucuna ulaşılmıştır.

\section{Bulgular ve Tartışma}

Bu çalışmada, GDBA'nın esneklik özellikleri elde edildikten sonra, temel ve alt temel tabanında esneklik özellikleri laboratuvar çalışması ile önceden belirlenmiş GDBA kullanılarak dizayn edilen bir esnek yol kaplama kesiti üzerinde tamamen doğrusal olmayan bir yöntem kullanılarak sayısal analiz gerçekleştirilmiştir. Elde edilen sonuçlar geçmiş çalışmalardan doğal ve GDBA için elde edilen sonuçlar, ilgili teoriler ve şartnameler ile değerlendirilerek, ülkemizdeki kentsel dönüşüm projesinden elde edilen GDBA'ların esnek yol kaplaması temel ve alt temel tabakalarında kullanım uygunluğu değerlendirilmiştir. 
Yol kaplama tabakalarında GDBA doğal agregalar yerine veya belli oranlarda doğal agregalar ile karıştırılarak kullanılabilmektedir [13]. Temel tabakasında yaygın olarak kullanılan Sınıf 5 ve Sınıf 6 doğal agregalar için elde edilen esneklik özellikleri, bu çalışmada kullanılan \%100 GDBA'dan hazırlanan temel numuneleri için elde edilen özet esneklik modülleri ve plastik deformasyon değerleri ile karşılaştırılmıştır. Çalışmada kullanılan \%100 GDBA ile hazırlanmış temel numuneleri için özet esneklik modülleri ve plastik deformasyon değerleri sırasıyla yaklaşık $154 \mathrm{MPa}$ ve $\% 0.09$ olarak bulunurken; Wen ve Edil [34] Sınıf 6 doğal agregası için bu değerlerin sirasıyla $154 \mathrm{MPa}$ ve $\% 0.71$ olduğunu, Bozyurt vd. [35] ise Sinıf 5 doğal agregası için ise bu değerlerin sirasiyla $152 \mathrm{MPa}$ ve \%1.60 olduğunu belirtmiştir. GDBA'nın doğal agregaya kıyasla daha eşit veya yüksek esneklik modülü ve daha düşük plastik deformasyon değerlerine sahip olduğu belirlenmiştir. Bu sonuçlar GDBA'nın doğal agregaya kıyasla eşit veya daha yüksek esneklik modülü ve daha düşük plastik deformasyon değerlerine sahip olduğunu ve GDBA'nın doğal Sınıf 5 ve Sınıf 6 agregalara kıyasla tekerlek izine karşı daha dirençli olduğunu göstermektedir.

Çevre dostu geri dönüştürülmüş malzemelere olan talebin artmasıyla birlikte, GDBA'nın alt temel ve temel tabakalarında kullanımı son yıllarda birçok araştırmacı tarafindan incelenmiş ve yol kaplama tabakalarında kullanım uygunluğu değerlendirilmiştir [36, 37, 38]. Geçmiş çalışmalardan elde edilen sonuçlar bu çalışmalardan elde edilen sonuçlar ile karşılaştırıldığında, elde edilen esneklik modülü ve plastik deformasyon değerlerinin kabul edilebilir seviyede olduğunu göstermektedir. Örneğin; Bozyurt vd. [36], farklı sahalardan toplanan altı farklı GDBA numunesi üzerinde çalışmış ve GDBA numuneleri için ÖEM ve birikmiş plastik deformasyonun (tekerlek izi) sırasıyla 163 ila $208 \mathrm{MPa}$ ve $\% 0.5$ ila $\% 0.8$ arasında değiştiğini bildirmiştir. Ayrıca geçmişte yapılan çalışmalar, esneklik modülü tahmini için bu çalışmada seçilen modellerin gelişmiş korelasyon parametrelerinin GDBA'nın esneklik modülünü tahmin etmek için başarıyla kullanıldığını ortaya koymuştur. Örneğin; Bozyurt vd. [35] yol kaplama temel tabakasında GDBA'nın kullanımını incelemiş, 7 farklı kaynaktan temin edilen GDBA'nın esneklik modülü tahminde MEPD modelin başarılı bir şekilde uygulanabileceği sonucuna varmıştır. Jayakody vd. [2] ise yol dolgu malzemesi olarak GDBA'nın performansını değerlendirmiş, esneklik modülü tahmininde bu çalışmada kullanılan Üssel, Uzan ve MEPD modelleri kullanış ve bu modellerin GDBA'nın esneklik modülü tahmininde başarılı bir şekilde kullanıldığını belirtmiştir.

Temel ve alt temel tabakalarının plastik davranışını değerlendirmek için ise Shakedown teorisi kullanılmaktadır [39, 40]. Bu teoriye göre, malzemelerin plastik deformasyon davranışı, Aralık A, Aralık B ve Aralık C olarak sınıflandırılmaktadır. Aralık A'da yer alan bir malzeme yalnızca sınırlı sayıda yük tekrarı için plastik davranış gösterirken ve bu sayıdan sonraki yük tekrarlarında elastik davranış sergilemektedir. Plastik sünme olarak adlandırılan B Aralığı'nda ise, malzemeler başlangıçta görece yüksek seviyede plastik deformasyon yaparken, yük tekrar sayısı arttıkça plastik deformasyon değerleri sabit kalmaktadır. C grubundaki malzemelerde ise yüksek yük seviyelerinde artan tekrar sayısı ile her zaman plastik davranış görülmektedir. Werkmeister [41] tarafindan, belirli sayıdaki yük tekrarlarındaki kalıcı deformasyon değerlerini kullanarak plastik davranışı değerlendirmek için Aralık A, B ve C için sırasıyla Eş. 10, 11 ve 12' de belirtilen sınır değerleri önerilmiş̧ir.

$$
\begin{aligned}
& \text { Aralık A: } \varepsilon_{\mathrm{p} 5000}-\varepsilon_{\mathrm{p} 3000}<0.045 \times 10^{-3} \\
& \text { Aralık B: } 0.045 \times 10^{-3}<\varepsilon_{\mathrm{p} 5000}-\varepsilon_{\mathrm{p} 3000}<0.40 \times 10^{-3} \\
& \text { Aralık C: } \varepsilon_{\mathrm{p} 5000}-\varepsilon_{\mathrm{p} 3000}>0.40 \times 10^{-3}
\end{aligned}
$$

Plastik deformasyon deneyinden elde edilen plastik deformasyon değerleri kullanılarak, 5000 ve 3000 yükleme tekrarları arasındaki plastik deformasyon değerleri arasındaki farkın, temel ve alt temel numunelerin için sirasıyla $0.095 \times 10^{-3}$ ve $0.075 \times 10^{-3}$ olduğu belirlenmiştir. Hem temel hem de alt temel numuneleri nihai plastik deformasyonun değerlerinin \%90'dan fazlasını 2500 yük tekrar sayısına kadar karşılamış ve bu yük tekrar sayısından sonra plastik deformasyon değerlerinde kayda değer bir değişiklik gözlenmemiştir. Bu durum temel ve alt temel numunesinin plastik sünme davranışı sergilediği göstermektedir. Benzer sonuçlar geçmişteki çalışmalar da elde edilmiş; Mohammadinia vd. [42], Shakedown teorisini kullanarak çok aşamalı döngüsel yükleme koşulları altında GDBA'nın plastik davranışını değerlendirmiş ve GDBA'nın farklı yükleme koşulları altında plastik davranışının A veya B 
Aralığında değerlendirilebileceği sonucuna varmıştır. Shakedown teorisini kullanan Saberian ve Li [43] ise kullandıkları GDBA'nın Aralık B'de yer aldığını yani plastik sünme davranışı sergilediğini bildirmiștir.

Ülkemizde kullanımda olan Karayolları Teknik Şartnamesi [44] ve AASHTO Kaplama Yapıları Tasarımı Rehberi [21] dikkate alınarak GDBA'nın kullanım uygunluğu değerlendirildiğinde, GDBA'dan hazırlanan temel ve alt temel numunelerinin geoteknik özelliklerinin şartnamede belirtilen alt ve üst sınır değerler arasında yer aldığı belirlenmiştir. Ülkemizde henüz Esneklik modülü ve plastik deformasyon deneylerine dayanan; esneklik modülü, plastik deformasyon ve toplam biriken plastik deformasyon (tekerlek izi) için sınır değerlerin belirtildiği bir şartname henüz bulunmamakta olup, bu sonuçlar AASHTO Kaplama Yapıları Tasarımı Rehberi [21] ve NCHRP 1-37A [33]'te belirtilen sınır değerler ile karşılaştırılmıştır. Esneklik modülü değerlerine göre kullanım uygunluğu değerlendirildiğinde elde edilen sonuçların yukarıda belirtilen ilgili şartnamelerde sınır değerleri karşıladığı görülmektedir. Sayısal analizde $11 \mathrm{~mm}$ olarak elde edilen kaplamadaki maksimum tekerlek izi ise, AASHTO Kaplama Yapıları Tasarımı Rehberi [21] ve NCHRP 1-37A [33]'te belirtilen maksimum değerler olan $11.51 \mathrm{~mm}$ ve $19.05 \mathrm{~mm}$ 'den daha düşüktür. Bu sonuçlar, kullanılan GDBA'nın esnek yol kaplama temel ve alt temel tabakasında kullanımının esneklik özellikleri açısından bir sorun teşkil etmediğini göstermektedir.

\section{Sonuç ve Öneriler}

Bu çalışmada, inşaat atıklarından elde edilen çevre dostu bir malzeme olarak geri dönüştürülmüş beton agregalarının (GDBA) esneklik özellikleri ve bu özelliklerin esnek yol kaplama tabakalarının mekanik davranışı üzerindeki etkileri araştırılmıştır. Bu amaçla, GDBA ile hazırlanmış temel ve alt temel numunelerinin, esneklik modülü ve kalıcı deformasyon deneyleri ile belirlenmiş esneklik özellikleri 3 boyutlu doğrusal olmayan sayısal analizlerde kullanılarak esnek yol kaplama tabakalarında çoklu tekerlek yükleri altında biriken plastik deformasyon değerleri yani tekerlek izleri belirlenmiştir.

Laboratuvar deney sonuçları, \%100 GDBA kullanılarak hazırlanan temel numunelerinin esneklik özelliklerinin alt temel numunesine kıyasla daha iyi olduğunu göstermesine rağmen hem alt temel hem de temel numunelerinin esneklik özelliklerinin doğal agregalar ile karşılaştırabilir seviyede olduğunu göstermiştir. Esneklik modülünü tahmin etmek için kullanılan çeşitli modeller arasında, laboratuvar deneylerinde ölçülen esneklik modülü ile MEPD modelde tahmin edilen arasında çok iyi bir uyum olduğu bulunmuş ve sayısal analizde MEPD modelinde elde edilen model parametreleri kullanılmıştır. \%100 GDBA kullanılarak hazırlanan temel tabakasında üretilen toplam tekerlek izinin, \%100 GDBA kullanılarak hazırlanan alt temel tabakasında üretilen toplam tekerlek izinden daha küçük olduğu görülmüştür. Plastik deformasyon değerleri kullanılarak, temel ve alt temel numunelerinin davranışı, Shakedown teorisi kullanılarak açıklanmış ve temel ve alt temel numunelerinin plastik sünme davranışı sergilediği sonucuna varılmıştır. 3 boyutlu sayısal analizler, alt temel ve temel tabakalarında elde edilen toplam tekerlek izinin laboratuvar sonuçlarından biraz daha yüksek olduğunu göstermesine rağmen, tüm kaplama tabakalarında elde edilen toplam tekerlek izi değerleri ilgili şartnamelerde belirtilen sınır değerleri karşılamaktadır. Bu sonuçlar, GDBA'nın temel ve alt temel tabakalarında kullanımının esneklik ve geoteknik özellikler açısından uygun olduğunu göstermektedir. Laboratuvardan elde edilen esneklik özellikleri ve esneklik modülü tahmininde kullanılan model parametreleri, bu çalışmada kullanılan GDBA için geçerlidir. Farklı kaynaklardan elde edilen geri dönüştürülmüş malzemeler kullanılmadan önce bu özelliklerin esneklik modülü ve kalıcı deformasyon deneyleri ile belirlenmesi tavsiye edilmektedir.

\section{Teşekkür}

$\mathrm{Bu}$ çalışmada laboratuvar deneylerinin gerçekleştirilmesi için İstanbul Teknik Üniversitesi Bilimsel Araştırma Projeleri Koordinasyon Birimi tarafından verilen desteğe yazarlar teşekkür ederler.

\section{Yazarların Katkısı}

Yazarlar bu araştırma makalesine eşit katkı sunmuşlardır. 


\section{Çıkar Çatışması Beyanı}

Yazarlar arasında herhangi bir çıkar çatışması bulunmamaktadır.

\section{Araştırma ve Yayın Etiği Beyanı}

Yapılan çalışmada araştırma ve yayın etiğine uyulmuştur.

\section{Kaynaklar}

[1] Cabalar A.F., Zardikawi O.A.A., Abdulnafaa M.D. 2017. Utilisation of Construction and Demolition Materials with Clay for Road Pavement Subgrade. Road Materials and Pavement Design, 20 (3): 702-714.

[2] Jayakody S., Gallage C., Ramanujam J. 2019. Performance Characteristics of Recycled Concrete Aggregate as an Unbound Pavement Material. Heliyon, 5 (9): e02494.

[3] Mohammadinia A., Arulrajah A., Sanjayan J., Disfani M. M. 2016. Stabilization of Demolition Materials for Pavement Base/Subbase Applications Using Fly-Ash and Slag Geopolymers: Laboratory Investigation. Journal of Materials in Civil Engineering, 28 (7): 1-9.

[4] Kawalec J., Kwiecien S., Pilipenko A., Rybak J. 2017. Application of Crushed Concrete in Geotechnical Engineering-Selected Issues. World Multidisciplinary Earth Sciences Symposium (WMESS 2017), 11-15 September, Prague-Czech Republic, 022057.

[5] Jiménez J. R., Ayuso J., Agrela F., López M., Galvín A.P. 2012. Utilisation of Unbound Recycled Aggregates from Selected CDW in Unpaved Rural Roads. Resources, Conservation and Recycling, 58: 88-97.

[6] Jayakody A., Gallage C., Kumar A. 2014. Assessment of Recycled Concrete Aggregates as a Pavement Material. Geomechanics and Engineering, 6 (3): 235-248.

[7] Mohammadinia A., Arulrajah A., Sanjayan J., Disfani M.M., Bo M.W., Darmawan S. 2015. Geotechnical Properties of Lightly Stabilized Recycled Demolition Materials in Base/Sub-Base Applications. International Foundations Congress and Equipmen, Expo, Reston, V.A., USA.

[8] López-Alonso M., Martinez-Echevarria M.J., Garach L., Galán A., Ordoñez J., Agrela F. 2019. Feasible Use of Recycled Alumina Combined with Recycled Aggregates in Road Construction. Construction and Building Materials, 195: 249-257.

[9] Beja I.A., Motta R., Bernucci L.B. 2020. Application of Recycled Aggregates from Construction and Demolition Waste with Portland Cement and Hydrated Lime as Pavement Subbase in Brazil. Construction and Building Materials, 258: 119520.

[10] Han Z., Zou W., Wang X. 2020. Predicting Water Retention Curve and Resilient Modulus of Compacted Natural and Recycled Pavement Unbound Granular Materials. International Journal of Pavement Engineering, 1477-268X (Online).

[11] Oskooei P.R., Mohammadinia A., Arulrajah A., Horpibulsuk S. 2020. Application of Artificial Neural Network Models for Predicting the Resilient Modulus of Recycled Aggregates. International Journal of Pavement Engineering, (Online).

[12] Ghorbani B., Arulrajah A., Narsilio G., Horpibulsuk S. 2020. Experimental Investigation and Modelling the Deformation Properties of Demolition Wastes Subjected to Freeze-Thaw Cycles Using ANN and SVR. Construction and Building Materials, 258: 119688.

[13] Arulrajah A., Piratheepan J., Disfani M.M., Bo M.W. 2013. Geotechnical and Geoenvironmental Properties of Recycled Construction and Demolition Materials in Pavement Subbase Applications. Journal of Materials in Civil Engineering, 25 (8): 1077-1088.

[14] Pourtahmasb M.S., Karim M.R., Shamshirband S. 2015. Resilient Modulus Prediction of Asphalt Mixtures Containing Recycled Concrete Aggregate Using an Adaptive Neuro-Fuzzy Methodology. Construction and Building Materials, 82: 257-263.

[15] Kaloop M.R., Gabr A.R., El-Badawy S.M., Arisha A., Shwally S., Hu J.W. 2019. Predicting Resilient Modulus of Recycled Concrete and Clay Masonry Blends for Pavement Applications Using Soft Computing Techniques. Frontiers of Structural and Civil Engineering, 13: 1379-1392. 
[16] Saberian M., Li J. 2019. Long-term Permanent Deformation Behaviour of Recycled Concrete Aggregate with Addition of Crumb Rubber in Base and Sub-Base Applications. Soil Dynamics and Earthquake Engineering, 121: 436-441.

[17] Pérez I., Medina L., Gómez-Meijide B., Costa P.A., Cardoso A.S. 2020. Numerical Simulation of Bitumen Emulsion-Stabilised Base Course Mixtures with C\&D Waste Aggregates Considering Nonlinear Elastic Behaviour. Construction and Building Materials, 249: 118696.

[18] Kim D., Norouzi A., Kass S., Liske T., Kim Y.R. 2017. Mechanistic Performance Evaluation of Pavement Sections Containing RAP and WMA Additives in Manitoba. Construction and Building Materials, 133: 39-50.

[19] Moazami D., Sahaf A., Moghaddam A.M. 2019. Investigating the Rutting Behavior of Modified Asphalt Mixtures with Waste Materials. Numerical Methods in Civil Engineering, 3 (4): 53-65.

[20] Hu X., Zhong S., Walubita L. F. 2015. Three-dimensional Modelling of Multilayered Asphalt Concrete Pavement Structures: Strain Responses and Permanent Deformation. Road Materials and Pavement Design, 71 (3): 1-14.

[21] American Association of State Highway and Transportation Officials. 1993. AASHTO Guide for Design of Pavement Structures. Washington D.C., USA.

[22] American Association of State Highway and Transportation Officials. 2017. AASHTO T-307, Standard Method of Test for Determining the Resilient Modulus of Soils and Aggregate Materials. Washington D.C., USA.

[23] Hicks R.G., Monismith C.L. 1971. Factors Influencing the Resilient Properties of Granular Materials. Transportation Research Record, 345: 15-31.

[24] Uzan J. 1985. Granular Material Characterization. Transportation Research Record, 1022: 52-59.

[25] Transportation Research Board National Research Council. 2004. Guide for MechanisticEmpirical Design of New and Rehabilitated Pavement Structures, NCHRP Report 01-37A, Washington, D.C., USA.

[26] Transportation Research Board National Research Council. 2003. Guide for MechanisticEmpirical Design of New and Rehabilitated Pavement Structures, NCHRP Report 01-28A, Washington, D.C., USA.

[27] Khogali W.E.I., Mohamed E.H.H. 2007. Novel Approach for Characterization of Unbound Material. Journal of the Transportation Research Board, 1874: 38-46.

[28] Haider I., Kaya Z., Cetin A., Hatipoglu M., Cetin B., Aydilek A.H. 2014. Drainage and Mechanical Behavior of Highway Base Materials. Journal of Irrigation and Drainage Engineering, 140 (6): 04014012.

[29] Bestgen J.O., Hatipoglu M., Cetin B., Aydilek A.H. 2016. Mechanical and Environmental Suitability of Recycled Concrete Aggregate as a Highway Base Material. Journal of Materials in Civil Engineering, 28 (9): 04016067.

[30] Stolle D., Guo P., Liu Y. 2009. Resilient Modulus Properties of Granular Highway Materials. Canadian Journal of Civil Engineering, 36 (4): 639-654.

[31] Rosa M.G., Cetin B., Edil T.B., Benson C.H. 2017. Freeze-Thaw Performance of Fly AshStabilized Materials and Recycled Pavement Materials. Journal of Materials in Civil Engineering, 29 (6): 04017015.

[32] Türk Standardları Enstitüsü. 2010. TS 3720-Bitümlü Karışımlar-Asfalt Betonu-Karışım Tasarımı Hesap Esaslar1-Marshall Yöntemi. Bakanlıklar, Ankara.

[33] Ishibashi I., Zhang X. 1993. Unified Dynamic Shear Moduli and Damping Ratios of Sand and Clay. Soils and Foundations, 33 (1): 182-191.

[34] Wen H., Edil T.B. 2009. Sustainable Reconstruction of Highways with In-Situ Reclamation of Materials Stabilized for Heavier Loads. BCR2A Conference, Champaign, Illinois, USA.

[35] Bozyurt O., Tinjum J.M., Son Y.H., Edil T.B., Benson C.H. 2012. Resilient Modulus of Recycled Asphalt Pavement and Recycled Concrete Aggregate. Geo-Congress, USA.

[36] Akbas M., Dayioglu A., Hatipoglu, M., Iyisan R. 2020. Beneficial Use of Recycled Concrete Aggregate as Base and Subbase Material in Turkey. American Society of Civil Engineers International Conference on Transportation and Development, May 26-29, Seattle, Washington, USA. 
[37] Sanger M., Natarajan B.M., Wang B., Edil T., Ginder-Vogel M. 2019. Recycled Concrete Aggregate in Base Course Applications: Review of Field and Laboratory Investigations of Leachate Ph. Journal of Hazardous Materials, 121562.

[38] Tuladhar R. Marshall A., Sivakugan N. 2020. Use of Recycled Concrete Aggregate for Pavement Construction. Advances in Construction and Demolition Waste Recycling, 181-197.

[39] Werkmeister S. 2006. Shakedown Analysis of Unbound Granular Materials using Accelerated Pavement Test Results from New Zealand's CAPTIF Facility. Geotechnical Special Publication, ASCE, Reston, VA.

[40] Erlingsson S., Rahman M. 2013. Evaluation of Permanent Deformation Characteristics of Unbound Granular Materials by means of Multistage Repeated-Load Triaxial Tests. Journal of the Transportation Research Board, 2369 (1): 11-19.

[41] Werkmeister S. 2003. Permanent Deformation Behavior of Unbound Granular Materials. Ph.D. Dissertation, Dresden University of Technology, Dresden, Germany.

[42] Mohammadinia A., Naeini M., Arulrajah A., Horpibulsuk S., Leong M. 2020. Shakedown Analysis of Recycled Materials as Railway Capping Layer under Cyclic Loading. Soil Dynamics and Earthquake Engineering, 139.

[43] Saberian M., Li J. 2019. Long-term Permanent Deformation Behaviour of Recycled Concrete Aggregate with Addition of Crumb Rubber in Base and Sub-Base Applications. Soil Dynamics and Earthquake Engineering, 121: 436-441.

[44] T.C Ulaştırma Bakanlığı Karayolları Genel Müdürlüğü. 2013. Karayolları Teknik Şartnamesi2013. https://www.tamyol.com.tr/ UserFiles/Content/KGM_Teknik_Sartnamesi_2013.pdf. Yayın tarihi (Erişim Tarihi: 23.11.2020). 